\title{
Would a euro's depreciation improve the French economy?*
}

\author{
Riccardo Magnani ${ }^{\dagger} \quad$ Luca Piccoli ${ }^{\ddagger}$ Martine Carré ${ }^{\S} \quad$ Amedeo Spadaro $₫$
}

May, 2013

\begin{abstract}
In this paper, we use a Micro-Macro model to evaluate the effects of a euro's depreciation on the French economy, both at the macro and micro level. Our Micro-Macro model consists of a Microsimulation model that includes an arithmetical model for the French fiscal system and two behavioral models used to simulate the effects on consumption behavior and labor supply, and a multisectoral CGE model which simulates the macroeconomic effects of a reform or a shock. The integration of the two models is made using an iterative (or sequential) approach. We find that a 10\% euro's depreciation stimulates the aggregate demand by increasing exports and reducing imports which increases production and reduces the unemployment rate in the economy. At the individual level, we find that the macroeconomic shock reduces poverty and, to a lesser extent, income inequality. In particular, the decrease in the equilibrium wage, determined in the macro model, slightly reduces the available income for people who have already a job, while the reduction in the level of unemployment permits to some individuals to find a job, substantially increasing their income and, in many cases, bringing them out of poverty.
\end{abstract}

Keywords: Exchange rates; Microsimulation; CGE models.

JEL Classification: F40; C63; C68.

${ }^{*}$ We are grateful to Philippe Aghion and Benjamin Carton for their useful comments. Luca Piccoli and Amedeo Spadaro acknowledge financial support from the Spanish Government (Grant ECO2011-28999). The usual disclaimer applies.

${ }^{\dagger}$ CEPN - Université Paris 13, France and CEPII, France. E-mail: riccardo.magnani@univ-paris13.fr.

${ }^{\ddagger}$ Universitat de les Illes Balears, Spain. E-mail: luca.piccoli@uib.es.

${ }^{\S}$ LEDa - Université Paris-Dauphine, France. E-mail: martine.carre-tallon@dauphine.fr.

"Universitat de les Illes Balears, Spain and PSE, France. E-mail: amedeo.spadaro@uib.es. 


\section{Introduction}

"Deficit scolds and inflation obsessives" are leading us "down the path to ruin" said recently Paul Krugman who advocates on his blog the use of an external devaluation for the Eurozone. Fifteen years ago, Obstfeld and Rogoff (1996) note in that sense that there was then overwhelming evidence suggesting that countries that abandoned gold early in the Great Depression and inflated did much better than countries that tried to stay linked to gold. Evidence from the interwar years provides some of the strongest support for a systematic effect of monetary policy on output. It is interesting to contrast this view with the older view of Nurkse (1944), who viewed devaluation as a "beggar-thy-neighbor" strategy that raises the devaluer's income mainly at trading partners' expense. Indeed, the standard macroeconomic effects of a devaluation are an increase in exports and in production of tradable goods, and an improvement of the external position. ${ }^{1}$

However, as pointed out by Edwards (1986), the nominal depreciation may produce in some cases a negative effect on total production. This situation, denoted as a contractionary devaluation, can be caused by the fact that nominal devaluation determines a reduction in the aggregate domestic demand (i) because domestic prices increase, or (ii) because there is a redistribution of incomes from individuals with low marginal propensity to save to individuals with high marginal propensity to save (Krugman and Taylor, 1978). In addition, the effect of nominal devaluation on the current account, and then on the economic activity, can be positive but very small in real terms and negative in nominal terms in the case in which the import and export elasticities are sufficiently low. Moreover, the increase in foreign prices reduces the demand for the foreign intermediate goods implying a reduction in total production.

Econometric analyzes are also mixed. Edwards (1986) estimates the effect of a real exchange rate variation on real output growth on twelve developing countries from 1965 to 1980 . He finds that current devaluation has a negative effect on economic growth while the past devaluation produces a positive effect. The total effect is estimated to be nil. Gylfason and Risager (1984) incorporate the link between devaluation, foreign interest payments, and the current account into a fairly general macroeconomic model in which variations in the exchange rate affect aggregate demand through exports, imports, and expenditure as well as aggregate supply via the cost of imported factors of production. On the basis of available statistical estimates of the behavioral and structural parameters of the model, they try to assess the empirical importance of this link in a group of highly indebted industrial and developing countries. By and large, the empirical results indicate that high foreign debt and interest payments tend to reduce the short- to medium-run effect of devaluation on national income, especially in the LDCs, but make little difference to its generally positive effect on the current account.

Another relevant aspect of currency devaluation is that it is by definition an asymmetric shock which affects the relative prices between monetary zones but also between sectors. Concerning

\footnotetext{
${ }^{1}$ Instead, in the long run and in the case of full employment, the effect of the nominal depreciation is simply an increase in domestic prices, implying that the shock has no effect on the real exchange rate and then on the economic activity.
} 
the economic consequences at the sectoral level, Gourinchas (1999) states that a variation in the real exchange rate provokes a reallocation of production factors across tradable and nontradable sectors. Campa and Goldberg (2001) show that low price-over-cost-markup industries like textiles, lumber and wood products, and primary metal or fabricated metal products - exhibit more statistically significant responses to exchange rates than do higher markup industries. The real wage elasticities of response are systematically larger as industries increase their export orientation and systematically smaller (and even turn negative) as industries rely more heavily on imported inputs. For instance, they found that for an export oriented and lower mark up industry with a $30 \%$ export share and a $10 \%$ import share, the estimated employment increase from a $10 \%$ dollar depreciation is $2.4 \%$. International evidence on the effects of exchange rates on labor markets is provided among others by Burgess and Knetter (1998) who focus on the G7 countries. They confirm differences among industries in employment elasticities with respect to exchange rates, but also across countries.

Starting from these works, we analyze the consequences of currency devaluation for the French economy. The equilibrium real exchange rate guarantees the equilibrium of the current account for the entire Eurozone but, if we consider EU member states separately, it produces important surpluses or deficits. ${ }^{2}$ This is why the analysis of the economic consequences of the euro's depreciation is relevant for a country like France in which the current account displayed important deficits starting from $2005^{3}$ while, in the first period of the introduction of the euro, the current account has produced important surpluses.

Our analysis is carried out by using an integrated Micro-Macro simulation approach. ${ }^{4}$ Our Micro-Macro model, focused on the French economy, consists of a Microsimulation model that includes an arithmetical model for the French fiscal system and two behavioral models used to simulate individual consumption behavior and individual labor supply discrete choices, and of a multisectoral and static CGE model with two foreign zones (the Eurozone and the rest of the world). The integration of the two models is made using an iterative (or sequential) approach.

Even if the majority of international trade is with other EU members, euro's devaluation induces important macroeconomic effects by considering that France imports some fundamental

\footnotetext{
${ }^{2}$ While nominal exchange rates are pegged within the euro area, real effective exchange rates have continued to vary given the disparities in inflation rates. Using a Behavioral Equilibrium Exchange Rate approach on the period 1980-2010 Coudert et al. (2012) analyze real exchange rate misalignments for euro area countries. They find that currency misalignments have been increased on average for all euro area countries since the monetary union, with different patterns. In particular, the peripheral member countries (Greece, Ireland, Italy, Spain and Portugal) have suffered from increasingly overvalued exchange rates since the mid-2000s.

${ }^{3}$ The current account deficit represented $0.6 \%$ of GDP in 2005 and has continually increased until $2008(2.1 \%$ of GDP). In 2010, it represented $2.3 \%$ of GDP.

${ }^{4}$ The integration between microsimulation models and general equilibrium models appears very appealing since, on one side, microsimulation models suffer the fact that the analysis is implicitly carried out in a partial equilibrium framework (i.e. the effects on the individual behavior are computed without taking into account for the general equilibrium effects that the change in individual behavior determines at the macro level) and, on the other side, general equilibrium models suffer the fact that they are based on the representative agent paradigm. The integration between these two types of models allows to avoid the previous shortcomings: the individual effects are computed by taking into account for the general equilibrium effects and the macro effects are computed by taking into account for the individual heterogeneity instead of using a representative agent.
} 
inputs, like oil, in dollars. It is then interesting to evaluate the effects of such an inflationary shock (i) on macroeconomic variables such as GDP, current account, employment and real wages, the relative competitiveness of domestic enterprises, and the purchasing power of households, (ii) on sectoral production and the allocation of production factors across tradable and non-tradable sectors, and (iii) on individual choices and, then, on income distribution, inequality and poverty. In particular, our model allows us to to investigate how the income distribution is affected by a macro shock such as currency devaluation and how inequalities, both in terms of consumption and incomes, change. In addition our model allows us to determine who win and loose from currency devaluation. This kind of analysis is fundamental since taking account for the redistributive effects of any reform is essential in a democratic decision-making process.

The effects of currency depreciation, and more generally of any shock, strongly depend on the closure rule used in the macro model. ${ }^{5}$ Devaluation improves the external financial position by increasing exports and reducing imports. In a neoclassical framework in which investments are savings-driven, the effect on real GDP is negligible (the only effects are due to the reallocation of factors across sectors) since (i) the production at the macro level depends on the supply of labor and capital that are supposed to be fully employed and (ii) the increase in one of the components of the aggregate demand is compensated by a strong reduction in investments and in consumption (see Hall, 2009). Thus, currency devaluation can stimulate real GDP only if the hypothesis of fullemployment of production factors is removed. There are different ways to consider involuntary unemployment. In particular, involuntary unemployment can be explained by the rigidity of wages (or by the presence of a wage bargaining mechanism) or by the weakness of the aggregate demand, according to the keynesian view. In the first case, currency devaluation, which produces a reduction in the demand for intermediate goods and then in the marginal productivity of labor, increases the level of unemployment. In the second case, currency devaluation, which stimulates net exports and then the aggregate demand, reduces the level of unemployment. Given that the empirical analysis supports the idea that currency devaluation positively affects the current account and stimulates production, we believe that the keynesian closure is more appropriate than the neoclassical one. ${ }^{6}$ However, as shown with a sensitivity analysis using the keynesian closure rule, the positive effect on the unemployment rate determined by currency devaluation is extremely high. This is why we chosen to use in our CGE model a closure rule which is between the neoclassical and the keynesian ones. In particular, we introduce in our model an investment function which takes into account for the (partial) crowding-out effect on investments produced by a change in the components of the aggregate demand.

\footnotetext{
${ }^{5}$ For a review of the macro closure rules see Löfgren et al. (2001), Rattso (1982) and Taylor and Lysy (1979).

${ }^{6}$ Rosensweig and Taylor (1990) used a CGE model with a keynesian closure to simulate the effect of currency devaluation in Thailand. They find that a $10 \%$ devaluation could increase real GDP by $3.3 \%$. More recently, Álvarez-Martínez and Polo (2012) simulate different external shocks affecting the aggregate demand (among which the reduction of exports) by using a neoclassical closure in which investments are savings-driven and a keynesian closure in which investments are fixed at a given value and the unemployment rate is endogenous. They conclude that using a neoclassical closure the model produces unrealistic changes in the level of investments, while using a keynesian closure the results in terms of GDP and unemployment are closed to empirical data recently observed.
} 
Our main results show that euro's depreciation stimulates the aggregate demand by increasing exports and reducing imports. In particular, using our Micro-Macro model calibrated to the French economy, we find that a 10\% euro's devaluation stimulates real GDP $(+0.6 \%)$ and reduces unemployment (-1.8 pp). We also find that euro's depreciation induces significant effects at the sectoral level. The production of tradable sectors is stimulated while only the construction sector is affected by a dramatically job destruction due to the strong fall in investments. ${ }^{7}$ At the individual level, given the reduction in the unemployment rate determined at the macro level, some unemployed people find a job and, given the change in real wage and consumption prices determined at the macro level, the individual choices concerning labor supply and consumption demand are affected. We find a significant reduction of poverty and a slight reduction of income inequality. In particular, the decrease in the equilibrium wage determined in the macro model moderately reduces the available income for people who already have a job, while the more conspicuous reduction in unemployment permits to some individuals to find a job, substantially increasing their income.

The paper is organized as follows. In the next section we describe the main characteristics of our Micro-Macro model. Section 3 presents the results of our simulation, while Section 4 presents two sensitivity analyses. The last section concludes.

\section{The Micro-Macro model}

In this section, we first present our Microsimulation model, which includes an arithmetical model for the French fiscal. Then we present our multisectoral CGE model. Finally, we discuss the procedure used to integrate the two models.

\subsection{The SYSIFF 2006 behavioral microsimulation model}

SYSIFF 2006 (Système d'Imposition Fiscale Français) is an arithmetical microsimulation model for the French fiscal system integrated with two behavioral models concerning consumption and labor supply decisions. It is a microsimulation model since it is based on micro data on a sample of families representative of the French population. The arithmetical part of the model simulates, for each of these families, social contributions, income taxes, VAT, local taxes and social benefits due or to be received by the state. The behavioral part includes two different microeconometric estimations: a quadratic almost ideal demand system for consumption decisions and a discretechoice labor supply model with involuntary unemployment.

\footnotetext{
${ }^{7}$ Note that this negative effect is coherent with the evolution of the construction sector in the early years of the introduction of the euro. In fact, between 1999 and 2005, the size of the construction sector has significantly increased in the Eurozone. In particular, in this period, the contribution of the construction sector to the total value added has increased by $11 \%$ in the Eurozone and, more specifically, by $13 \%$ in France, by $39 \%$ in Ireland, by $18 \%$ in Italy, and by $72 \%$ in Spain. In contrast, it has decreased by $27 \%$ in Germany. One interpretation of the observed change in the size of the construction sector could be that the introduction of the euro has represented a currency appreciation for most of the Eurozone countries, excepted for Germany where the introduction of the euro has represented a currency devaluation.
} 
The SYSIFF 2006 model includes a VBA macro that is the heart of the whole Micro-Macro model. The Micro-Macro model is composed by separate independent modules: the arithmetical microsimulation model, the dataset, the consumption module, the labor supply module and the CGE macro model. The VBA macro links all the modules together allowing for the complete micro-macro integration. It is responsible of loading the micro data into SYSIFF 2006, to read the results of the arithmetical microsimulation model and pass them to the labor supply and then consumption modules, that in turns provides the respective behavioral reactions that are passed, together with arithmetic variations, to the CGE that computes macroeconomic variations, that are passed to the arithmetic model, and so on until the variations of all relevant variables are sufficiently stable. In other words, iterations stop when variations of variations are below a certain convergence criterion.

\subsubsection{The arithmetical model}

The arithmetical model is a collection of algorithms and parameters that allow to compute for each family the amount of social contributions, income taxes, local taxes, and social benefits for a given fiscal system. ${ }^{8}$ The micro data set used in our paper is the Budget de Familles 2006 (from now on BDF2006) by Insee, chosen in virtue of the fact that it is the unique dataset available in France with sufficient information to fulfill all the needs of such a complex fiscal system as the French one, together with data on family expenditure and labor supply of households members. ${ }^{9}$ Given this dataset, the natural choice for the reference fiscal system is the French 2006 one. SYSIFF 2006 allows to simulate all possible reforms, and allows to use any scenario as the baseline for comparisons.

When simulating a scenario, SYSIFF 2006 works with one household at a time, i.e. it computes the value of all the fiscal instruments of that scenario for just one household. The VBA macro is responsible to load, one by one, all the households into SYSIFF 2006 and to save the results in a separate file. The most important result is the total available income after taxes and benefits since variations in the available income affect both the consumption and the labor supply behaviors. Other information that must be included among the results, in order to be passed to the CGE module, are the amounts of social contributions (employer and employee), income taxes, and benefits paid and received by each household.

\subsubsection{The consumption module}

The estimation of consumption demand is based on the Almost Ideal Demand System proposed by Deaton and Muellbauer (1980) and extended by Banks et al. (1997) with the introduction a quadratic income term in the demand functions that fulfill the necessity of having a higher rank demand system (useful when Engel curves are non-linear). Along with the quadratic extension,

\footnotetext{
${ }^{8} \mathrm{~A}$ list of fiscal instrument modeled in SYSIFF 2006 is reported in Table $\mathbf{1}$.

${ }^{9}$ This feature is fundamental for the estimation of the demand system and labor supply functions necessary to integrate micro-level behavioral responses.
} 
we also introduce demographic heterogeneity through an income translating function, firstly introduced by Gorman (1976). To comply with homogeneity properties required by consumption theory, i.e. to respect linear homogeneity and Slutsky symmetry, the demand system is subject to a set of a-priori restrictions on the parameters. The system of demand equations is estimated simultaneously by Full Information Maximum Likelihood, and a generalized Heckman correction for zero expenditures (Shonkwiler and Yen, 1999) is applied.

The demand of good $i$, in terms of budget share $w_{i}$, is specified as follows:

$$
w_{i}=\alpha_{i}+t_{i}(\mathbf{d})+\sum_{j} \gamma_{i j} \ln p_{j}+\beta_{i}\left(\ln y^{*}-\ln a(\mathbf{p})\right)+\frac{\lambda_{i}}{b(\mathbf{p})}\left(\ln y^{*}-\ln a(\mathbf{p})\right)^{2},
$$

with

$$
\begin{aligned}
t_{i}(\mathbf{d}) & =\sum_{r} \tau_{i r} \ln d_{r} \\
\ln y^{*} & =\ln y-\sum_{i} t_{i}(\mathbf{d}) \ln p_{i} \\
\ln a(\mathbf{p}) & =\sum_{i} \alpha_{i} \ln p_{i}+\frac{1}{2} \sum_{i} \sum_{j} \gamma_{i j} \ln p_{i} \ln p_{j} \\
\ln b(\mathbf{p}) & =\sum_{i} \beta_{i} \ln p_{i} .
\end{aligned}
$$

Where $\mathbf{d}$ is the vector of demographic characteristics, $\mathbf{p}$ is the vector of prices, and $y$ is total expenditure in consumption. The preference parameters to be estimated are $\alpha_{i}, \beta_{i}, \gamma_{i j}, \lambda_{i}$ and $\tau_{i r}$. To respect linear homogeneity and Slutsky symmetry the following restrictions must hold:

$$
\sum_{i} \alpha_{i}=1 ; \sum_{i} \beta_{i}=0 ; \sum_{i} \lambda_{i}=0 ; \sum_{i} \gamma_{i j}=0 \forall j ; \sum_{j} \gamma_{i j}=0 \forall i ; \gamma_{i j}=\gamma_{j i} \forall i, j ; \sum_{i} \tau_{i r}=0 \forall r .
$$

The dataset used for the estimation is BDF2006. After eliminating a few outliers, families with negative expenditures or negative total expenditure, the sub-sample consists of 10125 families, which is more than $99 \%$ of the original sample. To be consistent with the CGE model, consumption goods are aggregated into 11 categories: food, drinks, tobacco, clothing, housing, health care, transport/energy, communication, leisure, food out of home, and other goods. The demographic characteristics included are household size, number of children with less than 3 years, number of children aged between 3 and 6 , living in a city with more than 100 thousands inhabitants, age of the household head, if household head is married, if the household head is self-employed and if the household head is a manager.

The estimation results, reported in Table 2 in the Appendix, show that most parameters of the demand system are significantly different from zero and with expected signs. In addition, self-selection bias due to zero expenditure is detected (and corrected) for almost all goods. The 
signs of income and uncompensated price elasticities, reported in Table $\mathbf{3}$ in the Appendix, for the average family, are as expected and conform to consumption theory requirements. To integrate consumer reaction in the micro-macro model we use family specific elasticities rather than average elasticities. After a shock the quantities consumed by each family are computed according to income and prices variations and then sent to the CGE module for the evaluation of macro reactions and to continue iterations. This allows for a more detailed micro analysis of the behavioral response that accounts for differences in households income and characteristics.

\subsubsection{The labor supply module}

A standard way to estimate labor supply is to consider that individuals choose the optimal number of hours worked in order to maximize their well-being under a budget constraint. The non-linearity and non-convexity of the budget constraint, due to the characteristics of the tax system, implies the impossibility to derive an explicit solution to this standard utility maximization problem. For this reason, the best option for estimating labor supply behavior is that of discrete choice models à la Van Soest (1995). This approach allows to directly estimate the utility function parameters without the need of a Marshallian labor supply function. In particular, discrete choice models have the advance of capturing behavioral change in corner solution, accounting for market rigidities and avoiding the computational and analytical difficulties arising from non-linear and non-convex budget constraints, since the budget constraint is computed by the microsimulation model and introduced directly into the utility function.

The analysis of the distribution of the work alternatives has lead to the choice of four work alternatives: not to work (0 hours), 50\% part-time (18 hours), $80 \%$ part-time (28 hours), and full time (36 hours). Clearly, not everybody chose one of this options, so we set-up intervals within which the assigned choice is one of the four. 0 hours is reserved to non-working people, $50 \%$ part-time is for people working less than 23 hours per week, $80 \%$ part-time is for people working 23 to 33 hours per week, and full-time work is for those working more than 33 hours per week. To avoid inconsistencies with the predicted income of the alternatives we recalculate hourly wages of each individual such that the new wage multiplied by the hours of work corresponding to the assigned choice is equal to the observed salary.

The estimates of labor supply are performed on a sub-sample of potential wage earners ${ }^{10}$ separately for single men, single women and couples. In particular, for each single (man or woman) we define a utility level for each of the four alternatives depending on individual characteristics and the yearly disposable income associated to each alternative. In contrast, for each couple, we estimate the work decision jointly by considering eight alternatives, four for the woman and two (full time work or not to work) for the man. Then, we define a utility level for each of the eight alternatives depending on families characteristics and the yearly disposable income of the family associated to each alternative. Of course, in order to compute the disposable income for the non-

\footnotetext{
${ }^{10}$ We exclude from the sample self-employed, retired people, individuals with less than 25 years or over 60 years.
} 
observed alternatives it is necessary to generate a potential salary for the unemployed. Potential salaries are estimated using a Heckman correction model (Heckman, 1979) and the estimation results are reported in Table 4.

With respect to the standard model proposed by Van Soest (1995), which implicitly assumes that non-working people choose not to work, we consider that unemployment may be involuntary, as in Magnac (1991), Bingley and Walker (1997), and Haan and Uhlendorff (2007). Our micro data set allow us to identify involuntary unemployed by checking if individuals perceive an unemployment benefit (Allocation chômage) that is given only to people who are actively searching for a job. In our sample, $19.7 \%$ of individuals do not work and $6.3 \%$ of the sample is involuntary unemployed, implying that the unemployment rate is $7.3 \%$. Involuntary unemployment is introduced by randomly assigning (respecting the actual distribution of observed choices) a choice among the work alternatives to involuntary unemployed and estimating the discrete choice labor supply on these fictitious choices. The involuntary unemployment status is then set back according to an estimated probability of being unemployed. The probability of being unemployed has been estimated using a probit model and the predicted probabilities are used to rank individuals. The CDF of predicted probabilities of involuntary unemployment are used to set back the state of involuntary unemployment depending on the macroeconomic equilibrium level of unemployment. For instance, if a shock modifies the unemployment rate computed at the macro level, some individuals may find a job (if the unemployment rate decreases), or lose their job (if the unemployment rate increases), depending on their ranking in the CDF.

The estimation results are as expected since the probability of not being involuntary unemployed significantly increases with age and education, ${ }^{11}$ while it decreases if the person is an immigrant or if he has bad health conditions. Living in Paris has a positive but not significant impact on the probability of not being unemployed.

Preference parameters of the labor supply discrete choice model are estimated on the fictitious choice using a Multinomial Logit regression, such that individual chooses the alternative that maximizes his utility. Once the model is estimated the correct prediction is quite large, $88 \%$ for single men, $72 \%$ for single women and $53 \%$ for couples. To ensure that $100 \%$ of correct prediction is achieved, 300 extreme-value distributed stochastic terms are extracted for each choice, conditioned on the fact that the prediction corresponds to the observed choice. This error term represents the unobservable characteristics that are not explained by the model. The 300 extractions ensure the statistical properties of labor supply predictions once an exogenous shock or a reform changes the available income of the individuals.

The most relevant parameter in these estimates is the income parameter. We expect it to be positive and significant. This is so for single women and couples, while for men it is not significantly different from zero, probably due to the fact that the vast majority of single men are full time workers. Tables $\mathbf{5}$ and $\mathbf{6}$ report the estimated parameters for singles and couples

\footnotetext{
${ }^{11}$ We estimate this probability instead of the probability of being unemployed because we need a proper indicator to be compared with the macro unemployment rate. A lower value lowers the position in the CDF.
} 
respectively.

\subsection{The CGE model}

The CGE model, that represents the macro component of our Micro-Macro simulation model, is a multisectoral and static model with two foreign zones: the Eurozone and the rest of the world. The model is built by using the 2006 French input-output data-set provided by Insee. The inputoutput table, which includes 118 sectors, is aggregated into 19 sectors, 11 of which correspond to the sectors used in the Microsimulation model concerning the consumption decisions. The construction of the SAM (Social Accounting Matrix), necessary to calibrate our CGE model, is completed by using national accounts concerning the government account and the balance of payments. The complete description of the model could be found in the Annex of the paper.

\subsubsection{Production side}

The sectors of the CGE model are indicated in Table 7 in the Appendix. For each sector, we use a multi-stage CES production function. In the first stage, the demand of total intermediate goods $Z_{i}$, labor $L_{i}$ and capital $K_{i}$ is optimally chosen by each sector $i$ in order to maximize his profit given a technological constraint represented by the following production function:

$$
Y_{i}=\left[\left(\alpha_{Z, i}\right)^{\frac{1}{\sigma_{i}}} \cdot Z_{i}^{\rho_{i}}+\left(\alpha_{L, i}\right)^{\frac{1}{\sigma_{i}}} \cdot L_{i}^{\rho_{i}}+\left(\alpha_{K, i}\right)^{\frac{1}{\sigma_{i}}} \cdot K_{i}^{\rho_{i}}\right]^{\frac{1}{\rho_{i}}}
$$

In the second stage, each sector $i$ chooses the repartition of the total intermediate good into different intermediate goods sold by sector $j, Z_{j i}$. The choice is made in order to minimize the total cost and to respect the following constraint:

$$
Z_{i}=\left[\sum_{j}\left(\alpha_{Z_{j i}}\right)^{\frac{1}{\sigma Z_{i}}} \cdot Z_{j i}^{\rho Z_{i}}\right]^{\frac{1}{\rho Z_{i}}}
$$

In the third stage, each sector $i$ chooses the repartition of the intermediate goods sold by sector $j$ between the quantity that comes from the domestic market $Z_{j i}^{h}$ and from abroad $Z_{j i}^{f}$. The repartition is made in order to minimize the total cost and to respect the following constraint:

$$
Z_{j i}=\left[\left(\alpha_{j i}^{h}\right)^{\frac{1}{\sigma Z_{j i}}} \cdot\left(Z_{j i}^{h}\right)^{\rho Z_{j i}}+\left(\alpha_{j i}^{f}\right)^{\frac{1}{\sigma Z_{j i}}} \cdot\left(Z_{j i}^{f}\right)^{\rho Z_{j i}}\right]^{\frac{1}{\rho Z_{j i}}}
$$

In the last stage, each sector $i$ chooses the repartition of the intermediate goods sold by sector $j$ that come from abroad between the quantity that comes from the Eurozone $Z_{j i}^{E z}$ and from the rest of the world $Z_{j i}^{R o w}$. The repartition is made in order to minimize the total cost and to respect the following constraint: 


$$
Z_{j i}^{f}=\left[\left(\alpha_{j i}^{E z}\right)^{\frac{1}{\sigma Z_{j i}^{f}}} \cdot\left(Z_{j i}^{E z}\right)^{\rho Z_{j i}^{f}}+\left(\alpha_{j i}^{R o w}\right)^{\frac{1}{\sigma Z_{j i}^{f}}} \cdot\left(Z_{j i}^{R o w}\right)^{\rho Z_{j i}^{f}}\right]^{\frac{1}{\rho Z_{j i}^{f}}}
$$

The optimal repartition depends on the relative price, i.e. the ratio between the price in the Eurozone $P_{j}^{E z}$ and the world price expressed in euros $P_{j}^{R o w} \cdot \varepsilon$. In particular, (i) the nominal exchange rate $(\varepsilon)$ is assumed to be exogenous (while financial flows are endogenously determined in order to equilibrate the balance of payments) given that it is used to simulate the macroeconomic shock in our model. (ii) The world price of good $j$ expressed in foreign currency $\left(P_{j}^{R o w}\right)$ is exogenous. (iii) The price in the Eurozone $\left(P_{j}^{E z}\right)$ is treated as endogenous since it is reasonable to assume that euro's depreciation would affect prices in the whole Eurozone. In particular, for each sector $j$, the price in the Eurozone $P_{j}^{E z}$ is computed as a weighted average between a domestic price in the Eurozone (which is assumed to vary in the same proportion as the domestic price in France) and the world price expressed in euros. This implies that we consider in our model a symmetric equilibrium in the sense the euro's devaluation does not affect competitiveness within the Eurozone.

A fraction of the production is sold in the domestic market and the complementary fraction is exported. Goods that are exported are supposed to be identical to those sold in the domestic market, implying that the selling price is the same. Exports, towards the Eurozone and the rest of the world, are defined by a demand function that is decreasing in the relative price, i.e. the ratio between the domestic price and the foreign price expressed in domestic currency.

$$
\begin{aligned}
E_{i}^{E z} & =\alpha_{i}^{E z} \cdot\left[\frac{P_{i}^{E z}}{P_{i}^{h}}\right]^{\sigma E_{i}} \\
E_{i}^{\text {Row }} & =\alpha_{i}^{\text {Row }} \cdot\left[\frac{P_{i}^{\text {Row }} \cdot \varepsilon}{P_{i}^{h}}\right]^{\sigma E_{i}}
\end{aligned}
$$

Considering that euro's devaluation represents a shock affecting the whole Eurozone, it is reasonable to presume that also real GDP in the Eurozone is affected by the shock. For this reason, the terms $\alpha_{i}^{E z}$, which represent a measure of the purchasing power in the Eurozone, are assumed to be endogenous and to vary in the same proportion as the French real GDP.

\subsubsection{Demand side}

\section{(a) Consumption}

Concerning households, we consider one representative agent who supplies labor and capital and maximizes his well-being by choosing the consumption level of different goods and services. In particular, the quantity of labor that people want to supply is determined by the Microsimulation model, while the unemployment rate can be exogenous or endogenous in the CGE model depending on the choice of the macro closure. Concerning the consumption of goods and services by the representative agent, as indicated in Table 7, we consider 11 "microsimulation sectors", the consumption level of which is fixed at the level determined by the Microsimulation model; and 8 
"CGE sectors", the consumption level of which is determined in the CGE model.

Even if the labor supply and the consumption demand for some sectors are treated as exogenous in the CGE model, it is important to highlight that this does not mean that these variables are exogenous in our Micro-Macro model. In fact, the value of these variables is computed in the Microsimulation model by taking into account for the individual behavior. The variations determined at the individual level are then aggregated and introduced into the CGE model as an exogenous shock.

Preferences of the representative agent are modeled using a multi-stage utility function. In the first stage, the representative agent determines the level of total consumption for the "CGE goods" $C^{c g e}$ as a fraction of the total disposable income. In the second stage, he decides, for each "CGE good" $i$, the optimal consumption $C_{i}^{c g e}$. In the third stage, he chooses the optimal repartition of the consumption demand of good $i$ between domestic goods $C_{i}^{h}$ and foreign goods $C_{i}^{f}$. In the last stage, the consumption demand of the foreign good $i$ is divided into foreign goods coming from the Eurozone $C_{i}^{E z}$ and from the rest of the world $C_{i}^{R o w}$.

(b) Investments

The second component of the aggregate demand is given by the investment. As for consumption, we use a multi-stage structure. In the first stage the aggregate investment $I$ is allocated into different sectors $I_{i}$. Then, we determine the repartition of the investment of good $i$ between investment coming from the domestic market $I_{i}^{h}$ and the foreign market $I_{i}^{f}$. In the last stage, the investment of the foreign good $i$ is divided into foreign investment goods coming from the Eurozone $I_{i}^{E z}$ and from the rest of the world $I_{i}^{\text {Row }}$.

(c) Government expenditure

The third component of the aggregate demand is given by the government expenditure. Here, we also use a multi-stage structure. In the first stage the total government expenditure $G$, that is determined in the model by assuming that the ratio with respect to real GDP remains constant, is allocated into different sectors $\left(G_{i}\right)$. Then we determine the repartition of the government expenditure of good $i$ between goods coming from domestic and foreign markets (respectively $G_{i}^{h}$ and $G_{i}^{f}$ ). In the last stage, the government expenditure of the foreign good $i$ is divided into foreign goods coming from the Eurozone $G_{i}^{E z}$ and from the rest of the world $G_{i}^{\text {Row }}$.

(d) Total demand

For each sector $i$, the total quantity demanded depends on the demand of the domestic good (that is given by the difference between the domestic production and exports) and on the demand of the foreign good. In particular, for each sector $i$, the total domestic demand of the domestic good $X_{i}^{h}$ is given by the sum of domestic intermediate goods, private and public consumption and investments. For each sector $i$, the total imports respectively from the Eurozone $M_{i}^{E z}$ and from the rest of the world $M_{i}^{\text {Row }}$ are given by the sum of intermediate goods, private and public consumption and investments imported respectively from the Eurozone and the rest of the world. 


$$
\begin{aligned}
X_{i}^{h} & =\sum_{j} Z_{i j}^{h}+C_{i}^{h}+I_{i}^{h}+G_{i}^{h} \\
M_{i}^{E z} & =\sum_{j} Z_{i j}^{E z}+C_{i}^{E z}+I_{i}^{E z}+G_{i}^{E z} \\
M_{i}^{\text {Row }} & =\sum_{j} Z_{i j}^{\text {Row }}+C_{i}^{\text {Row }}+I_{i}^{\text {Row }}+G_{i}^{\text {Row }}
\end{aligned}
$$

\subsubsection{Budget constraints}

(a) Household budget constraint

The gross income earned by the representative agent is given by the sum of labor and capital incomes earned in France and abroad, and of transfers from the government.

$$
\begin{aligned}
Y_{\text {gross }} & =w \cdot\left(1-\cot _{\text {empl }}\right) \cdot L_{F r-F r} \cdot(1-u)+w^{E z} \cdot L_{F r-E z} \\
& +r \cdot P I \cdot A_{F r-F r}+r^{R o w} \cdot \varepsilon \cdot A_{F r-R o w}+\Gamma_{m s}+\Gamma
\end{aligned}
$$

In particular, the labor incomes earned in France depend on the endogenous domestic wage $w$, on the contribution rate paid by the employees $\cot _{e m p l}$ and the quantity of labor supplied by French people who work in France $L_{F r-F r} \cdot(1-u)$. The latter variable depends on the quantity of labor that people decide to supply $L_{F r-F r}$ that is fixed at the level determined in the Microsimulation model, and on the unemployment rate $u$ which can be exogenous or endogenous according to the macro closure that is chosen in the CGE model. By assuming that French people who work abroad work in the Eurozone, labor incomes earned abroad depend on the exogenous foreign wage rate $w^{E z}$ and the exogenous quantity of labor supplied by French people who work abroad $L_{F r-E z}$. The capital incomes earned in France depend on the endogenous domestic interest rate $r$ and the value of assets owned by French people in France $A_{F r-F r}$, while the capital incomes earned abroad depend on the exogenous world interest rate $r^{\text {Row }}$, the nominal exchange rate $\varepsilon$ and the value of assets owned by French people in the rest of the world $A_{F r-R o w}$. We consider two types of transfers from the government: transfers $\Gamma_{m s}$ that affect the labor incomes (and thus the labor market choices), the value of which is fixed at the level determined in the Microsimulation model, and transfers $\Gamma$ that do not affect individual labor choices that are treated as exogenous.

The disposable income is computed as the difference between the gross income and taxes on labor and capital incomes:

$$
Y_{\text {disp }}=Y_{\text {gross }}-\operatorname{Tax}_{l a b}-\tau_{c a p} \cdot r \cdot P I \cdot A_{F r-F r}
$$

In particular, the value of the taxes on labor incomes $\operatorname{Tax}_{l a b}$ is fixed at the level determined in the Microsimulation model, while taxes on capital incomes are supposed to be proportional to the capital incomes earned, where $\tau_{c a p}$ is the tax rate on capital incomes. 
The budget constraint states that the difference between the disposable income and the consumption of goods and services represents private savings $S_{H}$ :

$$
S_{H}=Y_{d i s p}-\sum_{i} P C_{i} \cdot C_{i}
$$

(b) Government budget constraint

Government revenues come from direct taxes on labor and capital incomes, indirect taxes on production and on the value added, and social contributions on employers and employees, while government expenditures are represented by the total public expenditure $G$, interests on the public debt $B$ and transfers to households $\left(\Gamma_{m s}\right.$ and $\left.\Gamma\right)$. The difference between government revenues and expenditures determines public savings $S_{G}$ :

$$
\begin{aligned}
S_{G} & =\sum_{i} \tau_{y, i} \cdot P_{i}^{h} \cdot Y_{i} \\
& +\sum_{i} \tau_{V A T_{i}} \cdot\left[P_{i}^{h} \cdot\left(C_{i}^{h}+I_{i}^{h}+G_{i}^{h}\right)+P_{i}^{E z} \cdot\left(C_{i}^{E z}+I_{i}^{E z}+G_{i}^{E z}\right)+P_{i}^{\text {Row }} \cdot \varepsilon \cdot\left(C_{i}^{\text {Row }}+I_{i}^{\text {Row }}+G_{i}^{\text {Row }}\right)\right] \\
& +\operatorname{Tax}_{l a b}+\tau_{c a p} \cdot r \cdot P I \cdot A_{F r-F r}+\sum_{i} w \cdot\left(\cot _{p a t r}+\cot _{\text {empl }}\right) \cdot L_{i} \\
& -\left(P_{g} \cdot G+r \cdot B+\Gamma_{m s}+\Gamma\right)
\end{aligned}
$$

(c) Balance of payments

The balance of payments states that the current account surplus plus the capital account surplus must be equal to zero. In particular, the current account surplus is given by the net exports plus the net factor incomes from the rest of the world, while the capital account surplus is given by the net capital inflows, i.e. the difference between the flow of foreign assets to France $\Delta A_{\text {Row }-F r}$ and the flow of domestic assets to the rest of the world $\Delta A_{F r-R o w}$ :

$$
\begin{aligned}
& {\left[\sum_{i} P_{i}^{h} \cdot\left(E_{i}^{E z}+E_{i}^{\text {Row }}\right)\right]-\left[\sum_{i}\left(\sum_{j} P Z_{i}^{f} \cdot Z_{i j}^{f}\right)+P C_{i}^{f} \cdot C_{i}^{f}+P I_{i}^{f} \cdot I_{i}^{f}+P G_{i}^{f} \cdot G_{i}^{f}\right] } \\
+ & {\left[w^{E z} \cdot L_{F r-E z}+r^{\text {Row }} \cdot \varepsilon \cdot P I \cdot A_{F r-R o w}\right]-\left[w \cdot\left(1-\cot _{\text {empl }}\right) \cdot L_{\text {Row }-F r}+r \cdot P I \cdot A_{\text {Row }-F r}\right] } \\
+ & P I \cdot\left(\Delta A_{\text {Row }-F r}-\Delta A_{F r-R o w}\right) \\
= & 0
\end{aligned}
$$

Given that the nominal exchange rate $\varepsilon$ is assumed to be exogenous, implying that the real exchange rate does not adjust in order to guarantee the equilibrium of the balance of payments, and given that the flow of domestic assets to the rest of the world $\Delta A_{F r-R o w}$ is determined by the optimal asset allocation (see infra), the balance of payments determines the flow of foreign assets to France $\Delta A_{\text {Row }-F r}$. 


\subsubsection{Optimal asset allocation}

We assume that the representative agent has to choose, at the beginning of the period, how to allocate his (exogenous) initial wealth $A_{F r}$ between investments in France $A_{F r-F r}$ and abroad $A_{F r-R o w}$. We suppose that the two alternatives are not perfect substitutes and that the optimal allocation depends on the ratio between the rates of return on the two assets. In particular, the rate of return on assets invested in France is the (net of depreciation) marginal productivity of capital $r$, while the rate of return on assets invested abroad is given by the sum between the foreign interest rate $r^{\text {Row }}$ and the percentage variation of the exchange rate $\frac{\varepsilon-\varepsilon_{-1}}{\varepsilon_{-1}}$.

The total wealth owned by the representative agent at the beginning of the next period $A_{F r_{+1}}$, that is given by the initial total wealth $A_{F r}$ plus private savings $S_{H}$, must be also allocated between assets invested in France $A_{F r-F r_{+1}}$ and abroad $A_{F r-R o w+1}$, on the basis of the anticipated ratio between the rates of return. We consider extrapolative expectations implying that the anticipated rate of return on assets invested in France is fixed at the (net of depreciation) marginal productivity of capital of the first period; the anticipated foreign interest rate is fixed at the level of the first period; and the anticipated percentage variation of the exchange rate is fixed to zero.

The allocation of the total wealth in the two periods allows us to determine the flow of domestic assets to the rest of the world $\Delta A_{F r-R o w}$.

\subsubsection{Equilibrium conditions}

For each sector $i$, domestic prices $P_{i}^{h}$ adjust in order to guarantee the equilibrium between the quantity produced $Y_{i}$ and the domestic and foreign demands:

$$
Y_{i}=X_{i}^{h}+E_{i}^{E z}+E_{i}^{R o w}
$$

In the labor market, the total labor demanded by all the sectors $\sum_{i} L_{i}$ must be equal to sum between the quantity of labor supplied by French people (that depends on the quantity of labor, determined in the Microsimulation model, that French people want to supply $L_{F r-F r}$, and on the unemployment rate $u$ ) and the (exogenous) quantity of labor supplied by foreign people $L_{R o w-F r}$ :

$$
\sum_{i} L_{i}=L_{F r-F r} \cdot(1-u)+L_{R o w-F r}
$$

In the capital market, the total capital demanded by all the sectors $\sum_{i} K_{i}$ and by the government $B$ must be equal to sum between the capital supplied by French people $A_{F r-F r}$ (that depends on the optimal asset allocation choice) and the (exogenous) capital supplied by foreign people $A_{\text {Row-Fr: }}$ :

$$
\sum_{i} K_{i}+B=A_{F r-F r}+A_{R o w-F r}
$$


This equation determines the equilibrium domestic rate of remuneration of capital $r$.

Finally, the numéraire chosen is the domestic consumer price index. Thus, the depreciation of the nominal exchange rate, that is the macroeconomic shock simulated in this paper, implies a depreciation of the same magnitude of the real exchange rate.

\subsubsection{Macro closure}

The macroeconomic equilibrium condition states that aggregate investments must be equal to aggregate savings (i.e. the savings of the representative agent, of the government and with respect to the rest of the world):

$$
P I \cdot I=S_{H}+S_{G}+P I \cdot\left(\Delta A_{R o w-F r}-\Delta A_{F r-R o w}\right)
$$

The neoclassical closure, that is the most frequently used in general equilibrium models, implies that investments are then savings-driven, i.e. the macroeconomic equilibrium condition determines the aggregate investment. The use of the neoclassical closure implies that a shock which increases the value of a component of the aggregate demand (for example, an increase in the current account induced by currency devaluation) produces a strong and unreasonable effect on investments, while the effect on the GDP is negligible since GDP is determined by the supply of productive factors that are supposed to be fully employed in the economy. Thus, currency devaluation can stimulate real GDP only if the hypothesis of full-employment of production factors is removed, i.e. by introducing in the model the involuntary unemployment provoked, according to the keynesian view, by the weakness of the aggregate demand.

With respect to the neoclassical closure, the keynesian closure consists to introduce fix the level of investments at a predetermined level (see Álvarez-Martínez and Polo, 2012) and to endogenize the unemployment rate. The unemployment rate is then determined in order to satisfy the macroeconomic equilibrium condition between investments and aggregate savings, implying that aggregate production is demand-driven. In particular, and in contrast to neoclassical models, the macroeconomic equilibrium may be an under-unemployment equilibrium, implying that unemployment appears in the case in which the level of the aggregate demand is insufficient.

However, even the keynesian closure presents a major shortcoming since the reduction in the unemployment rate produced by the currency devaluation simulated in our paper would be excessively high. This is why we chosen to use in our CGE model a closure rule which is between the neoclassical and the keynesian ones. The idea is the following: with a neoclassical closure, in which investments are savings-driven, an increase in the current account (or in any other aggregate demand component such as the public expenditure) produces a crowding-out effect on investments; in contrast, with a keynesian closure, the same shock produces no effects on investments (if investments are fixed at a given value) or just an indirect effect via the interest rate. Our idea is to introduce in our model an investment function which takes into account for the (partial) crowding-out effect on investments produced by a change in the components of the 
aggregate demand. Using quarterly French data from 1960 to 2011, we estimate the following investment function: ${ }^{12}$

$$
I=\alpha_{0}+\alpha_{1} \cdot G D P_{\text {real }}+\alpha_{2} \cdot r(-4)+\alpha_{3} \cdot C+\alpha_{4} \cdot G+\alpha_{5} \cdot C A
$$

Investments, in levels, are then explained by real GDP, the long-term interest rate with a lag of one year $r(-4)$, the aggregate consumption $C$, the total public expenditures $G$, and the current account $C A$. The results, reported in Table $\mathbf{8}$, show that an increase in each of the components of the aggregate demand produces a crowding-out effect on aggregate investments, but this crowding-out effect is only partial, i.e. is less important that the effect obtained using a neoclassical closure. The introduction of this investment function allows us to build a CGE model with a macro closure that is between the neoclassical and the keynesian ones.

\subsection{Integration of the two models}

Different procedures are used in the literature to integrate microsimulation and general equilibrium models: ${ }^{13}$ (i) The fully integrated approach consists to introduce in the CGE model all the individuals of the micro-data set (Cockburn, 2004). The problem of this approach may be related to the size of the model. (ii) The top-down approach (see for example Bourguignon et al., 2008) consists in transmitting the variations of macro variables computed in the CGE model into the microsimulation model. The problem of this approach is that there is no feedback from the microsimulation model back to the macro CGE model. (iii) The iterative (or sequential) approach, that is used in this paper, consists to transmit the variations of macro variables computed in the CGE model into the microsimulation model and to transmit the variations concerning the individual behavior computed in the microsimulation model into the CGE model, until the fixed point is reached (see for example Savard, 2003). (iv) Another approach, that permits to avoid the iterations between the microsimulation and the CGE models and to avoid the presence of a too much larger number of individuals in the CGE model, consists in using in the macro model several representative agents who aggregate the preferences of individuals who make discrete choices (Magnani and Mercenier, 2009).

Our Micro-Macro model works as follows. First, the CGE model simulates a shock (that can be a macroeconomic or a microeconomic shock) and determines the macroeconomic effect, in particular the percentage variations of (i) the equilibrium domestic wage, (ii) the equilibrium consumer prices of the goods and services, (iii) the consumer price index, and (iv) the equilibrium unemployment rate.

The percentage variations are then sent to the Microsimulation model in order to compute, for each individual, the effects on (i) the labor supply, (ii) the demand of goods and services, (iii) the employees' and employers' contributions, (iv) the taxes on incomes, and (v) the transfers from

\footnotetext{
${ }^{12}$ The equation estimated can be interpreted as a long-run relation since residuals are found to be stationary.

${ }^{13}$ For a review concerning the integration of microsimulation and CGE models, see Vaqar and O' Donoghue (2007).
} 
the government.

The individual effects are then aggregated and the percentage variations computed in the Microsimulation model allow us to determine the new values, used in the CGE model, of the following exogenous variables: (i) the total quantity of labor that people want to supply, (ii) the total demand of goods and services, (iii) the total contributions paid by the employees and the employers, (iv) the total taxes on incomes, and (v) the total transfers paid by the government.

The CGE model is then solved by considering the new values of the exogenous variables determined in the Microsimulation model. The solution obtained with the CGE model (i.e. the percentage variations of the equilibrium prices) is then introduced in the Microsimulation model again. And so on. We developed an algorithm in which the iterations are stopped when the fixed point is reached, i.e. when all the percentage variations remain (sufficiently) unchanged from one iteration to another.

\section{The effects of a macroeconomic shock: a euro's depreciation}

\subsection{Macroeconomic effects}

In this section we analyze the effects of a depreciation of the euro by $10 \%$. We first analyze the macroeconomic effects, both on the whole economy and at the sectoral level, and then the microeconomic effects.

\subsubsection{Macroeconomic effects on the whole economy}

The direct effect of the euro's depreciation concerns international trade. In particular, Table 9 shows that exports, at constant prices, increase by $3.2 \%$ while imports, at constant prices, decrease by $7 \%$. The effects in nominal terms are obviously less positive since the euro's depreciation implies an increase in the price of imports from the non-Eurozone. In nominal terms, imports decrease by $2.1 \%$, while exports increase by $3.5 \%$. The impact on the current account at constant prices is positive and quite important: with respect to GDP, the current account passes from a deficit of $0.5 \%$ before the shock to a surplus of $2.1 \%$ after the depreciation. Thus, the ratio of the current account to GDP increases, in real terms, by $2.6 \mathrm{pp}$.

Table 10 shows the main macroeconomic results. The increase of the current account in real terms stimulates the aggregate demand. Given the keynesian closure, the overall macroeconomic equilibrium between investments and savings is guaranteed by a change in the unemployment rate. In particular: (i) Private consumption in constant prices is negatively affected by the increase in the consumer price index $(+0.5 \%)$, but positively affected by the reduction in the unemployment rate. The private saving rate increases by $1.5 \mathrm{pp}$. (ii) Government savings decrease, at constant prices, and the ratio between the public deficit and GDP increases by $0.5 \mathrm{pp}$ given that (a) the aggregate public expenditure, that is supposed to be proportional to real GDP, increases by $0.6 \%$, (b) total direct taxation decreases by $0.5 \%$, and (c) transfers to families increase by $0.4 \%$. (iii) 
Savings with respect to the rest of the world are affected by (a) the flow of domestic assets to the rest of the world $(+2.4 \%)$ determined by the portfolio decision made by French people to invest in France or abroad and (b) the flow of assets from the rest of the world that equilibrates the balance of payments (-3.5\%). (iv) Investments, determined by a specific investment function, are negatively affected by the increase in consumption, in government expenditures and in the current account $(-11.3 \%)$. Nevertheless, it is important to note that the crowding-out effect on investments is less important than it could be by using a standard neoclassical closure. The macroeconomic equilibrium between investments and savings needs an important reduction in the unemployment rate from $8.8 \%$ to $7 \%(-1.8 \mathrm{pp})$.

Labor supply increases by $1.9 \%$ thanks to the reduction in the unemployment rate, even if the quantity of labor that workers want to supply decreases by $0.04 \%$ given the reduction in the real wage (-1.8\%). The economic mechanisms in the labor market are depicted in Figure 1. In particular, the labor demand function is determined such that the labor marginal productivity is equal to the real wage, while the quantity of labor supplied is positively related to the real wage. Before the shock, the economy is situated in point A in Figure 1. The weakness of the aggregate demand and production implies that the quantity of labor demanded is lower than the quantity of labor that is voluntary supplied at the initial real wage. The difference between people who want to work and people who find a job represents the involuntary unemployment, while the difference between the working-age population and people who want to work represents the nonparticipating population or voluntary unemployment. The euro's depreciation reduces the demand for intermediate inputs coming from the rest of the world. This reduces the marginal productivity of labor and causes a shift to the left of the labor demand function. Given that the shock increases exports and reduces imports, the aggregate demand for goods and services increases from $Y_{1}$ to $Y_{2}$ in the figure, and the demand of labor increases from $L_{1}^{d}$ to $L_{2}^{d}$. After the shock, the economy is situated in point $\mathrm{B}$, with a lower real wage, a greater level voluntary unemployment due to the reduction of the real wage, and a lower level of involuntary unemployment due to the increase in the aggregate demand.

Finally, the decrease in the unemployment rate produces a positive effect on the real GDP that increases by $0.6 \%$.

\subsubsection{Macroeconomic effects on the sectors}

As we have already said, the direct effect of depreciation concerns imports and exports. Obviously, the effect at the sectoral level depends on its exposure to international trade. Table 11 presents, for each sector, the size of imports (with respect to the total demand of domestic and foreign goods) and the size of exports (with respect to the total production). Seven sectors (energy, mineral products, textile, mechanic industry, electric industry, metallurgy, and transports) are exposed to international trade, while three sectors are completely closed to international trade 
(construction, hotels and restaurants, and public administration). ${ }^{14}$ The table also indicates the part of imports and exports with respect to the Eurozone and to the rest of the world. In the last column, we indicate the weight of each sector in terms of production with respect to the production at the national level.

Table 12 shows that euro's depreciation strongly reduces imports of tradable sectors from the rest of the world (energy $-7.3 \%$, mineral products $-5.4 \%$, textile $-9.4 \%$, mechanic industry $-11 \%$, electric industry $-10 \%$, metallurgy $-5.6 \%$, and transports $-6.7 \%$ ) that are partially replaced by imports from the Eurozone. Euro's depreciation stimulates exports toward the rest of the world.

Table 13 indicates other macroeconomic effects at the sectoral level, concerning the production level, labor and capital demand, consumption and investment. In particular, euro's depreciation induces a significant increase in the production of tradable sectors (energy $+2.1 \%$, mineral products $+2.5 \%$, textile $+4.5 \%$, electric industry $+3 \%$, metallurgy $+1.1 \%$ ). The production level of the construction sector is dramatically reduced $(-9.3 \%)$ due to the strong fall in investments.

The effect on sectoral prices are reported in Table 14. In particular the domestic price, for each sector, is endogenously determined to guarantee the equilibrium in the domestic market, while the foreign price is computed as the weighted average between the price in the Eurozone and the price in the rest of the world, both affected by the euro's depreciation. We also compute the total effect on the price level for each sector, computed as the weighted average between the domestic and the foreign prices, that is then sent to the Microsimulation model and affects the individual consumer behavior. The most important increases in prices are obtained the sectors that are more exposed to international trade: energy $+2 \%$, mineral products $+1.8 \%$, textile $+2.3 \%$, electric industry $+3.3 \%$, and transports $+3.1 \%$.

\subsection{Microeconomic effects}

The change in the real wage affects the disposable income earned by each family and then the labormarket choices. The change in consumer prices and the change in the disposable income earned by each family affect the consumption choices concerning the different goods and services. Moreover, a certain number of involuntary unemployed find a job, since the equilibrium unemployment rate decreases. This implies that the euro's depreciation, that is a pure macroeconomic shock, produces significant effects at the individual level, both in terms of individual choices and of income distribution.

Table 15 reports poverty and inequality measures for the whole population before and after the $10 \%$ depreciation of the euro, together with the percentage variation. ${ }^{15}$ The overall effects of the shock is rather limited. The most notable result is a reduction in the number of the poor ${ }^{16}$ of

\footnotetext{
${ }^{14} \mathrm{~A}$ sector is defined as exposed to international trade if imports represent more than $25 \%$ of total demand or exports represent more than $25 \%$ of total production.

${ }^{15}$ Poverty and inequality analysis is carried out by computing equivalent incomes using the OECD equivalence scale.

${ }^{16}$ Defined as the percentage of families with an equivalized disposable income below a poverty line corresponding to the $60 \%$ of the median equivalized disposable income.
} 
about $1 \%$, accompanied by a similar reduction in the intensity of poverty ${ }^{17}(-1.2 \%)$. Inequality reduction is small: the Gini index reduces by $0.3 \%$, while the average income increases for the first decile and reduces for the last, reducing the interdecile ratio by $0.7 \%$.

These figures are substantially driven by a significant reduction of involuntary unemployment. Tables 16 and 17 report the change in the labor supply for singles and couples. $1.4 \%$ of previously unemployed singles finds a full time job, while $0.3 \%$ find a part time job. Similarly, for couples, the families in which at least one member find a full time job are $1.2 \%$, while in the $0.4 \%$ of families a previously unemployed member finds a part-time job. The number of families that reduce the labor supply due to the decline of the salary is negligible.

These results imply that the number of families that gain from the shock is limited, but their gain is quite substantial. Table 18 reports the number of winners and losers in terms of disposable income and their gain by family type. In general, results confirm that who wins obtains substantial gains but that a rather large part of the population suffers from a moderate loss, due to the slight decrease in equilibrium wages. It is worth noting that the shock benefits mostly the poor. Almost $9 \%$ of the poor win and their gain in terms of available income represents more than $34 \%$. Another group that benefit from the shock is that composed by singles with children, although their gain is lower than for the poor, about $10 \%$ of single with children gain from the shock. The group that is less affected by the shock is that composed by the elderly. Since there is no behavioral variation in the labor supply and their pension is not affected by the shock, there is no variation in their conditions. ${ }^{18}$

Thus a first look at the aggregate poverty and inequality measures hides a quite substantial improvement. This is particularly true for poor people, since the reduction in the unemployment rate permits to some individuals to find a job. On the other side, the situation deteriorates - but very slightly - for people who have already a job since the wage level decreases after the shock. The average gain in terms of disposable income is very important $(+34.1 \%)$ for the winners, while the average loss is quite limited $(-1.1 \%)$ for the losers.

Finally, Table 19 reports the effects concerning consumption for each category by family type. Clearly, part of the variation is driven by price increase, especially for tobacco and clothing, that had the sharpest price increase, while large income increases beef up consumption of the poor.

\section{Sensitivity analysis}

In this section, we present two sensitivity analyses to explore the role of two key elements in the simulation of currency devaluation: the choice of the macro closure rule and the choice of the value of the elasticity used to model international trade.

\footnotetext{
${ }^{17}$ Defined as the mean distance separating the population from the poverty line, with the non-poor being given a distance of zero.

${ }^{18}$ In France pension benefits and subsidies are indexed with inflation, implying that the increase in prices obtained in the macro model has no effect on their real income.
} 
The first sensitivity analysis compares the results of our base scenario presented above with the ones obtained using different macro closure rules. As we have already said, in our base scenario we used a macro closure which can be considered as between the neoclassical and the Keynesian ones. Here we consider simulate the effects of a $10 \%$ euro's devaluation using a neoclassical closure, in which investments are determined by aggregate savings, and a Keynesian closure, in which investments are fixed at a predetermined value.

As Table 20 shows, using a neoclassical closure, euro's devaluation would produce a negative effect on real GDP (-0.6\%). This negative result is explained by the reduction in the stock of capital available in the economy $(-0.9 \%)$ which, in turns, is related to the choice of French people to invest abroad. Clearly, without this effect due to the optimal asset allocation, the effect on the real GDP would be negligible since, if aggregate labor and capital are constant, real GDP is affected only by the reallocation of the production factors across sectors. Thus, in real terms, the positive effect on the current account (exports increase by $2.6 \%$ and imports decrease by $8 \%$ ) is more than compensated by the small decrease in consumption and government expenditures and by the strong fall in investments $(-14.4 \%)$.

Instead, using a Keynesian closure rule, euro's devaluation produces a strongly positive effect on the real GDP. Even if the stock of capital decreases by $0.8 \%$, real GDP increases by $4.6 \%$ thanks to the strong increase in the labor endowment $(+8.6 \%)$ and the reduction in the unemployment rate (which passes from $8.8 \%$ to $0.9 \%$ ). Concerning the elements of the aggregate demand, the shock produces a positive effect on the current account (exports increase by $5.4 \%$ and imports decrease by $3.4 \%$ ), investments do not change since, with the Keynesian closure rule, are fixed at the initial level, consumption and government expenditures increase. To resume, we think that both the neoclassical and the Keynesian closures determine an unrealistic effect on real GDP. In particular, with the neoclassical closure the unrealistic effect is related to the excessively high reduction in investments, while with the Keynesian closure the unrealistic effect is related to the excessively high reduction in the unemployment rate. In contrast, in our base scenario, euro's devaluation produces a quite positive effect on real GDP combined with an important reduction in investments (even if the crowding-out effect on investments is less important than that obtained with the neoclassical closure rule) and with a reduction in the unemployment rate (which is less important than what that obtained with the keynesian closure rule).

The second sensitivity analysis concerns the elasticities used to model international trade. While in our base scenario we used the elasticities coming from the GTAP model, here we consider two scenarios in which these elasticities are multiplied by 0.5 and by 1.5. As Table 21 shows, in the first case the positive effect on the current account is less important than what obtained in the base scenario (exports increase by $1.6 \%$ vs. $3.2 \%$ in the base scenario, while imports decrease by $5.2 \%$ vs. $7 \%$ in the base scenario), while in the second case the effect is more important. Consequently, the effect on the real GDP and on the unemployment rate are less important in the first case (and more important in the second case) with respect to the base scenario. In particular, the positive effect on real GDP of a $10 \%$ euro's devaluation would be between $0.3 \%$ and $0.8 \%$ 
using elasticities between 0.5 and 1.5 times the GTAP elasticities.

\section{Conclusions}

In our paper, we use a Micro-Macro model to evaluate the effects of a pure macroeconomic shock represented by a $10 \%$ euro's depreciation, both at the macro and micro level. We find that euro's depreciation stimulates the aggregate demand by increasing exports and reducing imports. The increase in aggregate demand stimulates the real GDP and reduces the unemployment rate in the economy from $8.8 \%$ to $5.6 \%$. At the sectoral level euro's depreciation induces a significant increase in the production of tradable sectors (energy, mineral products, textile, mechanic industry, electric industry, metallurgy, and transports). As found by Davis and Haltiwanger (2001), currency devaluation induces important effects on job creation in tradable sectors, while the global effect on non-tradable sector is marginal. It is also interesting to note that currency devaluation does not produce a transfer of the workforce from non-tradable to tradable sectors. In fact, the strong job destruction produced in the construction sector seems to profit to all the other sectors, especially mineral products, textile and electric industry. Clearly, the strong reduction in the activity of the construction sector would have important consequences on the price of real estate.

At the individual level, we find that the macroeconomic shock induces significant consequences on poverty and a slight reduction of income inequality. The decrease in the equilibrium wage determined in the macro model moderately reduces the available income for people who have already a job, while the reduction in unemployment permits to some individuals to find a job, substantially increasing their income. The average income by decile always increases but for the poor it increases more than for the mid-class and the rich. In addition, a rather large part of the population suffers from a moderate loss, due to the decrease in equilibrium wages, while about $9 \%$ of the poor win and their gain in terms of available income represents more than $34 \%$.

\section{References}

Álvarez-Martínez, María Teresa and Polo, Clemente, (2012), A general equilibrium assessment of external and domestic shocks in Spain, Economic Modelling, 29, issue 6, p. 2486-2493.

Banks, James, Blundell, Richard and Lewbel, Arthur, (1997), Quadratic Engel Curves And Consumer Demand, The Review of Economics and Statistics, 79, issue 4, p. 527-539.

Bingley, Paul and Walker, Ian, (1997), The Labour Supply, Unemployment and Participation of Lone Mothers in In-Work Transfer Programmes, Economic Journal, 107, issue 444, p. 1375-1390.

Bourguignon, François J., Robilliard, Anne-Sophie and Robinson, Sherman, (2008), Examining the Social Impact of the Indonesian Financial Crisis Using a Macro-Micro Model, Open Access publications from Université Paris-Dauphine, Université Paris-Dauphine.

Burgess, Simon and Knetter, Michael M, (1998), An International Comparison of Employment Adjustment to Exchange Rate Fluctuations, Review of International Economics, 6, issue 1, p. 151-163. 
Campa, Jose Manuel and Goldberg, Linda S., (2001), Employment Versus Wage Adjustment And The U.S. Dollar, The Review of Economics and Statistics, 83, issue 3, p. 477-489.

Cockburn, John, (2004), Trade Liberalisation and Poverty in Nepal. A Computable General Equilibrium Micro Simulation Analysis, Development and Comp Systems, EconWPA.

Coudert, Virginie, Couharde, Cécile and Mignon, Valérie, (2012), On currency misalignments within the euro area, CEPII Working Papers, n. 7, April.

Davis, Steven and Haltiwanger, John, (2001), Sectoral job creation and destruction responses to oil price changes, Journal of Monetary Economics, 48, issue 3, p. 465-512.

Deaton, Angus S. and Muellbauer, John, (1980), An Almost Ideal Demand System, American Economic Review, 70, issue 3, p. 312-326.

Edward, Sebastian, (1986), Are Devaluations Contractionary?, The Review of Economics and Statistics, 68, issue 3, p. 501-508.

Haan, Peter and Uhlendorff, Arne, (2007), Intertemporal Labor Supply and Involuntary Unemployment, No 2888, IZA Discussion Papers, Institute for the Study of Labor (IZA).

Hall, Robert Ernest, (2009), By How Much Does GDP Rise If the Government Buys More Output?, Brookings Papers on Economic Activity, 40, issue 2 (Fall), p. 183-249.]

Gorman, William Moore, (1976). Tricks with utility functions. In M. J. Artis and A. R. Nobay (Eds.), Proceedings of the 1975 AUTE Conference, Essays in Economic Analysis. Cambridge: Cambridge University Press.

Gourinchas, Pierre-Olivier, (1999), Exchange rates do matter: French job reallocation and exchange rate turbulence, 1984-1992, European Economic Review, 43, issue 7, p. 1279-1316.

Gylfason, Thorvaldur and Risager, Ole, (1984), Does devaluation improve the current account?, European Economic Review, 25, issue 1, p. 37-64.

Krugman, Paul and Taylor, Lance, (1978), Contractionary effects of devaluation, Journal of International Economics, 8, issue 3, p. 445-456.

Löfgren, Hans, Harris, Rebecca Lee and Robinson, Sherman, (2001), A standard computable general equilibrium (CGE) model in GAMS, No 75, TMD discussion papers, International Food Policy Research Institute (IFPRI).

Magnac, Thierry, (1991), Segmented or Competitive Labor Markets, Econometrica, 59, issue 1, p. 165-187.

Magnani, Riccardo and Mercenier, Jean, (2009), On linking microsimulation and computable general equilibrium models using exact aggregation of heterogeneous discrete-choice making agents, Economic Modelling, 26, issue 3, p. 560-570.

Nurkse, Ragnar, (1944), International Currency Experience: Lessons of the Interwar Period, League of Nations.

Obstfeld, Maurice and Rogoff, Kenneth, (1996), Foundations of International Macroeconomics, The MIT Press.

Rattso, Jorn, (1982), Different macroclosures of the original Johansen model and their impact on policy evaluation, Journal of Policy Modeling, 4, issue 1, p. 85-97.

Rosensweig, Jeffrey A. and Taylor, Lance, (1990), Devaluation, Capital Flows, and Crowding-Out: A CGE Model with Portfolio Choice for Thailand, in Socially Relevant Policy Analysis, ed. by Lance Taylor, MIT Press (Cambridge, Mass. : 1990).

Savard, Luc, (2003), Poverty and Income Distribution in a CGE-Household Micro-Simulation Model: Top-Down/Bottom Up Approach, Cahiers de recherche, CIRPEE. 
Shonkwiler, J. Scott and Yen, Steven T., (1999), Two-Step Estimation of a Censored System of Equations, American Journal of Agricultural Economics, 81, issue 4, p. 972-982.

Taylor, Lance and Lysy, Frank J., (1979), Vanishing income redistributions: Keynesian clues about model surprises in the short run, Journal of Development Economics, 6, issue 1, p. 11-29.

Van Soest, Arthur, (1995), Structural Models of Family Labor Supply: A Discrete Choice Approach, Journal of Human Resources, 30, issue 1, p. 63-88.

Vaqar, Ahmed and O' Donoghue, Cathal, (2007), CGE-Microsimulation Modelling: A Survey, MPRA Paper, University Library of Munich, Germany. 
Table 1: Fiscal instruments simulated in SYSIFF 2006

\begin{tabular}{|c|c|}
\hline Social contributions and VAT & Income tax, local taxes and public benefits \\
\hline Employer social contributions & Deductions \\
\hline Assurance Maladie/Solidarité & Retraites complémentaire volontaire \\
\hline Assurance Vieillesse Plafonnée & Frais réels \\
\hline Assurance Vieillesse Déplafonnée & Abattement général \\
\hline Allocation Familiales & Déductions Enfant \\
\hline FNAL & Déductions Ascendants \\
\hline Allocation Chômage & Pertes en capital \\
\hline \multicolumn{2}{|l|}{ Retraites Complémentaire } \\
\hline AGFF & Income tax \\
\hline Régime de Prévoyance Cadres & Foyer fiscal \\
\hline Versement Transport & Impôt sur le Revenu \\
\hline \multicolumn{2}{|l|}{ Réduction Fillon } \\
\hline & Tax credits \\
\hline Employee Social contributions & Contribution non profit \\
\hline Assurance Maladie/Solidarité & Assurance décès-sante \\
\hline Assurance Vieillesse Plafonnée & Prestation compensatoire \\
\hline Assurance Vieillesse Déplafonnée & Personnes âgées dépendantes \\
\hline Allocation Chômage & Salarié à domicile \\
\hline Retraites Complémentaires & Garde d'enfants \\
\hline AGFF & Frais de scolarisation \\
\hline Assurance Santé extra/complémentaire & Comp. Taxe Carbone \\
\hline CAPS (Capital) & Réduction d'impôts DOM \\
\hline Prélèvement Social (Capital) & Prime pour l'emploi \\
\hline \multicolumn{2}{|l|}{ Allocations Familiales (self empl.) } \\
\hline Formation professionnelle (self empl.) & Local Taxes \\
\hline Assurance Maladie (self empl.) & Taxe Habitation \\
\hline Assurance Invalidité décès (self empl.) & Taxe Foncière sur le non-bâti \\
\hline Assurance Vieillesse (self empl.) & Taxe Foncière sur le bâti \\
\hline \multicolumn{2}{|c|}{ Régime d'Indemnités Journalières (self empl.) } \\
\hline & Public Benefits \\
\hline Special contributions & AF - Allocations Familiales \\
\hline CSG & PAJE - Prestation d'Accueil du Jeune Enfant \\
\hline \multirow[t]{2}{*}{ CRDS } & a) child born before $01-01-2004$ \\
\hline & APE (Allocation Parental d'Education) \\
\hline VAT & APJE (Allocation Pour Jeune Enfants) \\
\hline Food & AAM (Aide Assistant Maternelle) \\
\hline Beverages & b) child born after 01-01-2004 \\
\hline Clothing & Prime à la Naissance \\
\hline Energy & $\mathrm{AB}$ (Allocation de Base) \\
\hline Furniture & CLCA (Complément de Libre Choix d'Activité) \\
\hline Household appliance & Paje Emploi \\
\hline Housing (products) & CFAM - Complément Familial \\
\hline Health & API - Allocation Parent Isolée \\
\hline Transports & ARS - Allocation Rentrée Scolaire \\
\hline Communications & Prime de Déménagement \\
\hline Amusements & Minimum Vieillesse \\
\hline Books and newspapers & Aide au Logement \\
\hline Cinema & RMI (Revenu Minimum d'Insertion) \\
\hline Museums & RSA (Revenu de Solidarité Active) \\
\hline \multicolumn{2}{|l|}{ Leisure } \\
\hline \multicolumn{2}{|l|}{ Teaching } \\
\hline \multicolumn{2}{|l|}{ Meals } \\
\hline \multicolumn{2}{|l|}{ Beauty } \\
\hline Other goods & \\
\hline
\end{tabular}


Table 2: FIML estimation of the AIDS system

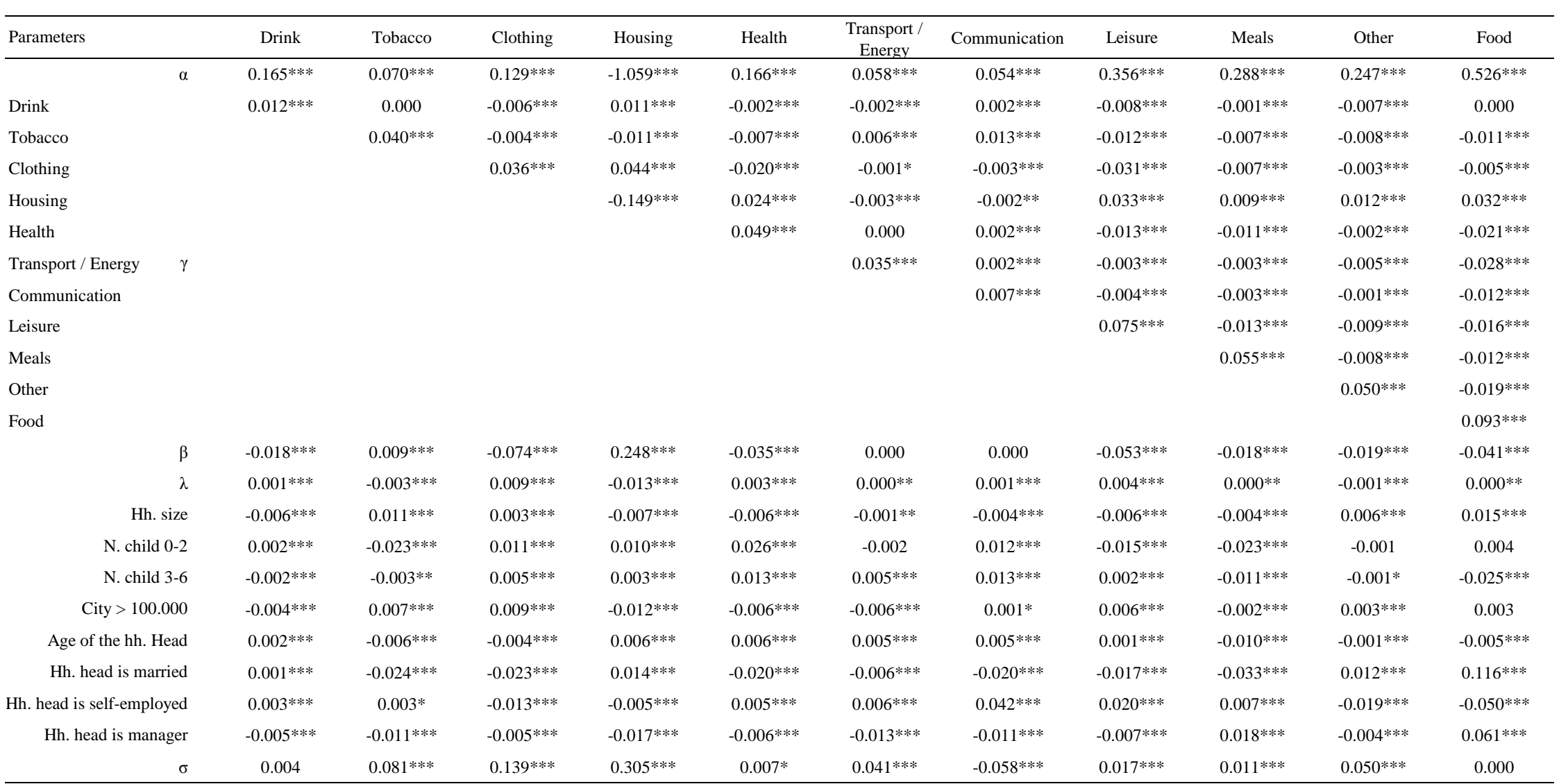


Table 3: Price and income elasticities from the estimation of the AIDS system

\begin{tabular}{|c|c|c|c|c|c|c|c|c|c|c|c|}
\hline & Drink & Tobacco & Clothing & Housing & Health & $\begin{array}{c}\text { Transport / } \\
\text { Energy }\end{array}$ & Communication & Leisure & Meals & Other & Food \\
\hline Income elasticities & 0.988 & 0.648 & 1.321 & 1.344 & 1.134 & 1.074 & 1.153 & 0.982 & 0.910 & 0.731 & 0.755 \\
\hline \multicolumn{12}{|c|}{ Uncompensated price elasticities } \\
\hline Drink & -0.794 & 0.045 & -0.037 & -0.100 & 0.004 & -0.014 & 0.032 & -0.072 & -0.019 & -0.056 & 0.021 \\
\hline Tobacco & 0.055 & -0.453 & -0.078 & -0.089 & -0.005 & 0.074 & 0.096 & -0.084 & -0.083 & -0.062 & -0.019 \\
\hline Clothing & -0.040 & -0.057 & -0.484 & -0.123 & -0.081 & -0.046 & -0.036 & -0.149 & -0.082 & -0.066 & -0.156 \\
\hline Housing & -0.081 & -0.078 & -0.140 & -0.270 & -0.105 & -0.079 & -0.049 & -0.166 & -0.122 & -0.117 & -0.137 \\
\hline Health & -0.007 & -0.031 & -0.063 & -0.078 & -0.529 & -0.019 & -0.004 & -0.084 & -0.083 & -0.021 & -0.213 \\
\hline Transport / Energy & -0.012 & 0.017 & -0.003 & -0.027 & -0.007 & -0.786 & 0.007 & -0.027 & -0.002 & -0.033 & -0.200 \\
\hline Communication & 0.028 & 0.116 & -0.024 & -0.044 & 0.002 & 0.014 & -0.741 & -0.110 & -0.099 & -0.036 & -0.260 \\
\hline Leisure & -0.035 & -0.092 & -0.110 & -0.107 & -0.056 & -0.017 & -0.035 & -0.336 & -0.066 & -0.053 & -0.076 \\
\hline Meals & -0.005 & -0.100 & -0.045 & -0.074 & -0.054 & 0.021 & -0.027 & -0.063 & -0.466 & -0.041 & -0.057 \\
\hline Other & -0.024 & -0.106 & -0.046 & -0.100 & 0.016 & -0.005 & 0.011 & -0.047 & -0.035 & -0.355 & -0.041 \\
\hline Food & 0.023 & -0.051 & -0.057 & -0.031 & -0.088 & -0.109 & -0.043 & -0.026 & -0.020 & -0.023 & -0.329 \\
\hline
\end{tabular}


Table 4: Heckman estimation for salaries

\begin{tabular}{|c|c|c|c|c|}
\hline & \multicolumn{2}{|c|}{ Single } & \multicolumn{2}{|c|}{ Married } \\
\hline & Female & Male & Female & Male \\
\hline \multicolumn{5}{|l|}{ Log of hourly wage } \\
\hline Age & $0.025^{*}$ & $0.037 * *$ & $0.046^{* * *}$ & $0.035 * * *$ \\
\hline Age squared & 0.000 & 0.000 & $0.000 * * *$ & $0.000 * * *$ \\
\hline Primary education & 0.020 & -0.090 & -0.050 & -0.023 \\
\hline Secondary education & 0.059 & 0.128 & 0.075 & $0.150 * * *$ \\
\hline Cap/Bep & 0.051 & $0.110^{*}$ & $0.101 * *$ & $0.135 * * *$ \\
\hline University & $0.196^{* *}$ & $0.253 * * *$ & $0.266 * * *$ & $0.235 * * *$ \\
\hline Superior education & $0.246 * * *$ & $0.248 * * *$ & $0.351 * * *$ & $0.246 * * *$ \\
\hline Stranger & -0.027 & $-0.133 * *$ & $-0.094 * *$ & $-0.063 * *$ \\
\hline Ile-de-France & 0.095 & 0.051 & 0.066 & $0.110^{* *}$ \\
\hline Public sector & $0.101 * * *$ & $0.084 *$ & $0.126 * * *$ & 0.011 \\
\hline White collar & $0.342 * * *$ & $0.406 * * *$ & $0.307 * * *$ & $0.406 * * *$ \\
\hline Constant & $1.344 * * *$ & $1.200 * * *$ & $0.791 * * *$ & $1.171 * * *$ \\
\hline \multicolumn{5}{|l|}{ Selection } \\
\hline Age & $0.121 * * *$ & 0.027 & $0.073 * * *$ & -0.001 \\
\hline Age squared & $-0.001 * * *$ & 0.000 & $-0.001 * * *$ & 0.000 \\
\hline Primary education & $0.552 * *$ & -0.055 & 0.237 & -0.042 \\
\hline Secondary education & $0.704 * * *$ & 0.105 & 0.147 & $0.476^{* *}$ \\
\hline Cap/Bep & $0.675 * * *$ & $0.622 * * *$ & $0.303 * * *$ & 0.184 \\
\hline University & $1.231 * * *$ & 0.194 & $0.686 * * *$ & $0.276^{* *}$ \\
\hline Superior education & $1.358 * * *$ & 0.423 & $0.726 * * *$ & $0.468 * * *$ \\
\hline Stranger & $-0.344 *$ & $-0.609 * * *$ & $-0.656^{* * *}$ & $-0.580 * * *$ \\
\hline N. children $[0,2]$ & -0.347 & -1.493 & $-0.459 * * *$ & $-0.206 * *$ \\
\hline N. children [3-6] & $-0.243^{* * *}$ & 2.961 & $-0.255^{* * *}$ & 0.027 \\
\hline Bad health & $-0.977 * * *$ & $-1.297 * * *$ & $-0.425^{* * *}$ & $-0.764 * * *$ \\
\hline Non-labor incomes & $-0.081 * * *$ & $-0.077 * * *$ & $-0.015 * * *$ & $-0.044 * * *$ \\
\hline Ile-de-France & 0.498 & 0.371 & -0.086 & 0.083 \\
\hline Constant & $-1.694 *$ & 1.397 & -0.238 & $2.000 * *$ \\
\hline$\rho$ & -0.018 & 0.008 & $0.236 * * *$ & -0.027 \\
\hline
\end{tabular}


Table 5: Discrete choice labor supply estimation for singles

\begin{tabular}{|c|c|c|c|c|c|c|c|c|}
\hline & \multicolumn{4}{|c|}{ Single females } & \multicolumn{4}{|c|}{ Single males } \\
\hline & Not working & $50 \%$ Part time & $80 \%$ Part time & Full Time & Not working & $50 \%$ Part time & $80 \%$ Part time & Full Time \\
\hline Ln of disposable income & Ref. cat & $0.444 * *$ & $0.444^{* *}$ & $0.444^{* *}$ & Ref. cat. & 0.012 & 0.012 & 0.012 \\
\hline Part time 1 & & 4.248 & -8.716 & $-13.233^{* *}$ & & -17.508 & $-2.692^{*}$ & $-2.620 * *$ \\
\hline Part time 2 & & 0.643 & $13.905 * * *$ & -0.846 & & -28.445 & -26.597 & -10.203 \\
\hline Domestic worker & & $-1.630^{*}$ & $-2.571 * *$ & $-1.833 * * *$ & & 1.024 & $43.158^{*}$ & $46.652 * *$ \\
\hline Baby sitter & & -0.590 & -0.226 & 0.222 & & -4.720 & $-55.798^{*}$ & $-58.848 * *$ \\
\hline Age & & 16.179 & $52.136^{* * *}$ & $31.865^{* * *}$ & & 0.588 & 1.261 & 0.952 \\
\hline Age squared & & -21.995 & $-65.668 * * *$ & $-40.839 * * *$ & & -0.123 & 0.444 & 0.603 \\
\hline Primary education & & 0.956 & 0.432 & $1.183^{*}$ & & -0.107 & 1.463 & 0.864 \\
\hline Secondary education & & 1.075 & $1.811 * * *$ & $1.393 * *$ & & -0.828 & 0.423 & 0.033 \\
\hline Cap/bep & & 0.412 & 0.537 & $0.995^{* *}$ & & $3.472 * * *$ & $3.873 * * *$ & $3.083 * *$ \\
\hline University & & $1.937 * * *$ & $1.701 * * *$ & $2.435^{* * *}$ & & 0.457 & -0.719 & -0.151 \\
\hline Superior education & & $2.231 * * *$ & $1.953 * * *$ & $2.482 * * *$ & & 27.561 & 24.387 & 23.462 \\
\hline Stranger & & 0.443 & 0.323 & -0.284 & & 6.360 & 6.020 & 5.558 \\
\hline N. Children [0-2] & & -0.078 & -0.247 & $-1.399 * *$ & & $-1.974 * * *$ & $-1.890 * * *$ & $-3.501 * * *$ \\
\hline N. Children [3-6] & & -0.247 & -0.341 & $-0.684 * * *$ & & $-0.114 * *$ & $-0.209 * * *$ & $-0.192 * * *$ \\
\hline Bad health & & $-2.096^{* * * *}$ & $-1.828^{* * * *}$ & $-2.421 * * *$ & & 0.523 & 0.064 & 0.486 \\
\hline Non-labor incomes & & -0.024 & $-0.061 * *$ & $-0.062 * * *$ & & -1.778 & 3.909 & 3.611 \\
\hline Rent & & $1.176^{* * * *}$ & $1.031 * * *$ & $1.284^{* * * *}$ & & 0.122 & -0.016 & -0.035 \\
\hline Museums & & -5.942 & -0.237 & -0.203 & & 0.078 & 0.060 & 0.098 \\
\hline Books & & 0.091 & 0.007 & 0.033 & & 0.870 & -6.748 & -4.295 \\
\hline Amusements & & -0.030 & $0.101^{*}$ & 0.050 & & 0.000 & 0.000 & 0.000 \\
\hline Constant & & -3.984 & $-10.827 * * *$ & $-4.316^{*}$ & & 0.000 & 0.000 & 0.000 \\
\hline
\end{tabular}


Table 6: Discrete choice labor supply estimation for couples

\begin{tabular}{|c|c|c|c|c|c|c|c|c|}
\hline \multirow{2}{*}{$\begin{array}{l}\text { Husband } \\
\text { Wife }\end{array}$} & \multicolumn{4}{|c|}{ Not working } & \multicolumn{4}{|c|}{ Full time } \\
\hline & Not working & $50 \%$ Part time & $80 \%$ Part time & Full Time & Not working & $50 \%$ Part time & $80 \%$ Part time & Full Time \\
\hline Ln of disposable income & ref cat. & $2.401 * * *$ & $2.401 * * *$ & $2.401 * * *$ & $2.401 * * *$ & $2.401 * * *$ & $2.401 * * *$ & $2.401 * * *$ \\
\hline Age wife & & 108.876 & $112.073^{*}$ & $76.146^{* *}$ & 7.236 & 20.030 & $42.130 *$ & $46.001^{* *}$ \\
\hline Age squared wife & & -108.164 & $-133.696^{*}$ & $-91.670^{* *}$ & -5.080 & -23.861 & $-50.852^{*}$ & $-56.638^{* *}$ \\
\hline Cap/bep wife & & -0.147 & 0.592 & 0.409 & -0.350 & -0.014 & 0.062 & -0.231 \\
\hline University wife & & -1.509 & -15.533 & 0.332 & -0.183 & 0.209 & 0.530 & 0.345 \\
\hline Superior education wife & & -1.273 & -15.412 & 0.543 & -0.731 & -0.473 & -0.314 & -0.427 \\
\hline Stranger wife & & 0.771 & -16.678 & -0.057 & 0.398 & 0.323 & -0.436 & -0.352 \\
\hline Bad health wife & & -0.724 & -18.028 & $-1.139 *$ & -0.298 & $-1.019 *$ & -0.636 & $-1.141 * *$ \\
\hline Age husband & & -5.975 & -47.364 & 5.005 & -26.819 & -22.964 & -29.254 & -35.180 \\
\hline Age squared husband & & -13.638 & 46.666 & -7.243 & 25.663 & 20.958 & 28.465 & 33.523 \\
\hline Cap/bep husband & & 0.806 & -0.309 & 0.270 & -0.730 & -0.732 & -0.386 & -0.489 \\
\hline University husband & & 0.782 & 1.047 & 0.861 & -0.501 & -0.282 & -0.017 & 0.116 \\
\hline Superior education husband & & -0.336 & -14.322 & -0.130 & -0.716 & -0.769 & -0.428 & -0.264 \\
\hline Stranger husband & & -1.091 & 0.455 & 0.234 & -0.272 & -0.180 & -0.313 & -0.192 \\
\hline Bad health husband & & 0.679 & 0.716 & $1.180^{* *}$ & $-1.513^{* * *}$ & $-1.531 * * *$ & $-1.355^{* * *}$ & $-1.441^{* * *}$ \\
\hline Part-time 1 & & $25.456^{*}$ & 11.706 & $17.557 * *$ & 7.210 & $15.523 * *$ & 6.507 & 4.120 \\
\hline Part-time 2 & & -8.738 & -1.448 & -6.806 & -4.783 & -2.856 & 1.891 & -5.125 \\
\hline Non-labour income & & $0.752^{* *}$ & 0.240 & 0.346 & $-0.610^{* * * *}$ & $-0.563^{* * *}$ & $-0.598 * * *$ & $-0.579 * * *$ \\
\hline Rent & & -0.414 & 0.353 & 0.175 & 0.251 & 0.253 & 0.525 & 0.472 \\
\hline Leisure & & 0.009 & -0.068 & 0.116 & 0.119 & $0.252^{* *}$ & $0.215^{*}$ & $0.272 * *$ \\
\hline Number of children & & -0.103 & -0.807 & $-0.554 *$ & 0.329 & -0.070 & -0.156 & $-0.525 * *$ \\
\hline Constant & & $-25.640^{*}$ & -13.958 & $-18.781 * * *$ & 6.585 & 2.082 & -0.897 & 3.067 \\
\hline
\end{tabular}


Table 7: List of the sectors in the CGE model

\begin{tabular}{|c|c|c|c|}
\hline & & $\mathrm{CGE}^{1}$ & $\mathrm{MS}^{2}$ \\
\hline 1 & Food & & $\mathrm{x}$ \\
\hline 2 & Beverage & & $\mathrm{x}$ \\
\hline 3 & Tobacco & & $\mathrm{x}$ \\
\hline 4 & Energy & $\mathrm{x}$ & \\
\hline 5 & Mineral products & $\mathrm{x}$ & \\
\hline 6 & Textile & & $\mathrm{x}$ \\
\hline 7 & Housing & & $\mathrm{x}$ \\
\hline 8 & Mechanic industry & $\mathrm{x}$ & \\
\hline 9 & Electric industry & $\mathrm{x}$ & \\
\hline 10 & Metallurgy & $\mathrm{x}$ & \\
\hline 11 & Health & & $\mathrm{x}$ \\
\hline 12 & Construction & $\mathrm{x}$ & \\
\hline 13 & Transports & & $\mathrm{x}$ \\
\hline 14 & Hotels et restaurants & & $\mathrm{x}$ \\
\hline 15 & Leisure & & $\mathrm{x}$ \\
\hline 16 & Communications & & $\mathrm{x}$ \\
\hline 17 & Public administration & $\mathrm{x}$ & \\
\hline 18 & Non-financial services and $R \& D$ & $\mathrm{x}$ & \\
\hline 19 & Financial services & & $\mathrm{x}$ \\
\hline
\end{tabular}

${ }^{1}$ CGE means that the consumption level of a sector is endogenously determined in the CGE model.

${ }^{2}$ MS means that the consumption level of a sector is fixed at the level determined by the Microsimulation model.

Table 8: Estimation results of the investment function

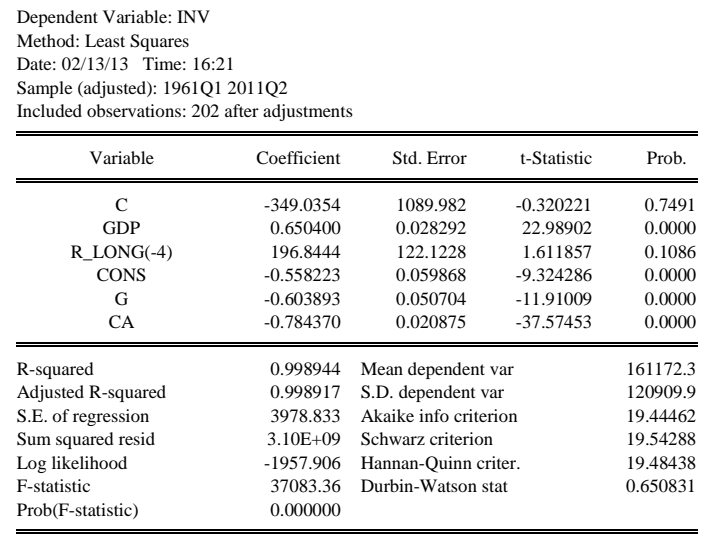

Source: Insee. French data from 1961q1 to 2011q2. 
Table 9: Aggregate effects of a $10 \%$ euro's depreciation on international trade

\begin{tabular}{llcc}
\hline & & constant prices / real terms & current prices / nominal terms \\
\hline Exports & (\% var) & 3.2 & 3.5 \\
Exports (Eurozone) & $(\%$ var $)$ & 1.1 & 1.5 \\
Exports (Rest of the world) & $(\%$ var $)$ & 5.5 & 5.7 \\
Imports & $(\%$ var $)$ & -7.0 & -2.0 \\
Imports (Eurozone) & $(\%$ var $)$ & 2.5 & 4.1 \\
Imports (Rest of the world) & $(\%$ var $)$ & -16.6 & -8.3 \\
Current Account / GPD & $(\%$ in p.p. & 2.7 & 1.5 \\
\hline
\end{tabular}

Table 10: Aggregate effects of a $10 \%$ euro's depreciation on the main macroeconomic variables

\begin{tabular}{lll}
\hline Real GDP & (\% var) & 0.6 \\
Unemployment rate & $(\%$ in p.p. $)$ & -1.8 \\
Labor & $(\%$ var $)$ & 1.9 \\
Capital & $(\%$ var $)$ & -0.8 \\
Real wage & $(\%$ var $)$ & -2.0 \\
Real rate of remuneration of capital & $(\%$ in p.p. $)$ & 0.0 \\
Consumer Price Index & $(\%$ var $)$ & 0.5 \\
\hline Private consumption & $(\%$ var $)$ & 0.1 \\
Investments & $(\%$ var $)$ & -11.2 \\
Government expenditure & $(\%$ var $)$ & 0.6 \\
\hline Private saving rate & $(\%$ in p.p. $)$ & 1.3 \\
Public deficit / GDP & $(\%$ in p.p. $)$ & 0.7 \\
Flow of domestic assets to RoW & $(\%$ var $)$ & 2.4 \\
Flow of foreign assets to France & $(\%$ var $)$ & -3.6 \\
\hline
\end{tabular}


Figure 1: The labor market with voluntary and involuntary unemployment

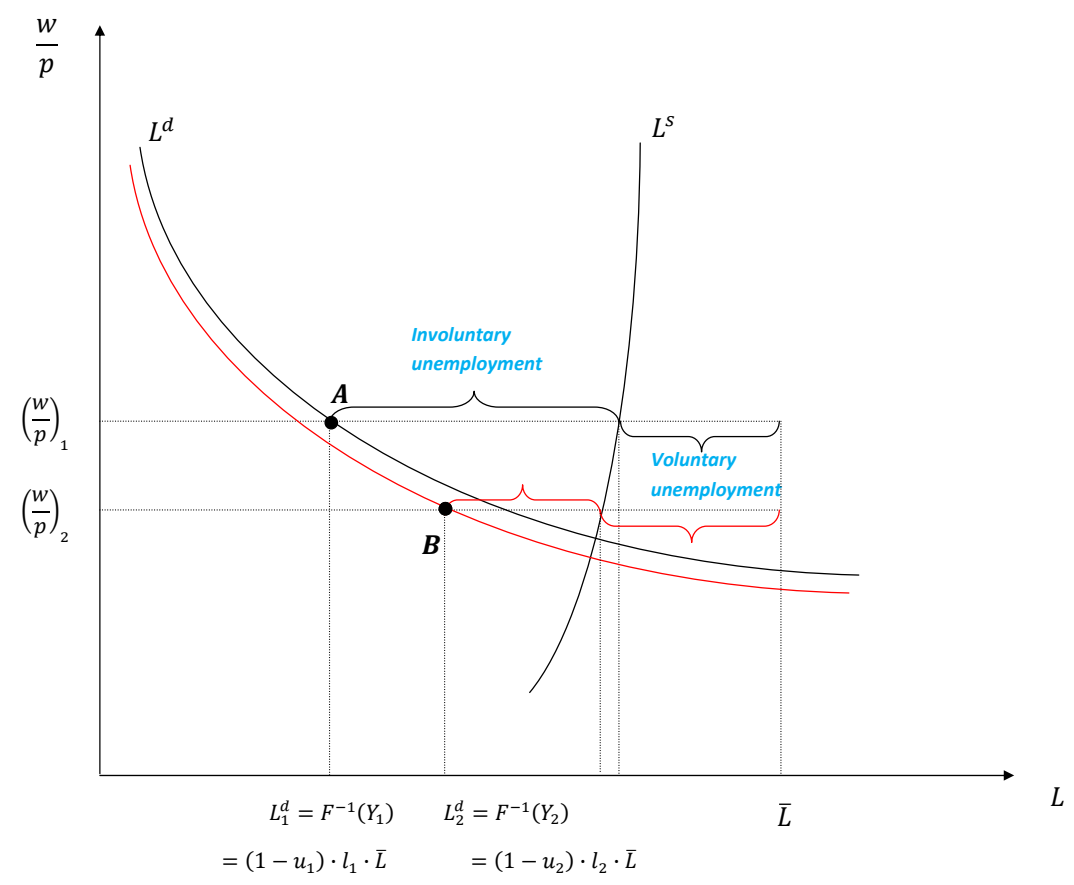

Table 11: Size of imports and exports (total, vs. Eurozone, vs. rest of the world)

\begin{tabular}{|c|c|c|c|c|c|c|c|c|}
\hline & & $\mathrm{M} /(\mathrm{M}+\mathrm{X})$ & $\mathrm{Meu} / \mathrm{M}$ & Mrow / M & $\mathrm{E} /(\mathrm{E}+\mathrm{X})$ & Eeu / E & ERow / E & $\mathrm{Y} / \mathrm{GDP}$ \\
\hline 1 & Food & $13.9 \%$ & $63.0 \%$ & $37.0 \%$ & $14.5 \%$ & $66.8 \%$ & $33.2 \%$ & $6.8 \%$ \\
\hline 2 & Beverage & $9.0 \%$ & $53.8 \%$ & $46.2 \%$ & $24.5 \%$ & $37.9 \%$ & $62.1 \%$ & $2.2 \%$ \\
\hline 3 & Tobacco & $13.1 \%$ & $83.3 \%$ & $16.7 \%$ & $3.3 \%$ & $51.8 \%$ & $48.2 \%$ & $0.4 \%$ \\
\hline 4 & Energy & $29.5 \%$ & $27.0 \%$ & $73.0 \%$ & $11.2 \%$ & $56.7 \%$ & $43.3 \%$ & $5.5 \%$ \\
\hline 5 & Mineral products & $46.5 \%$ & $57.7 \%$ & $42.3 \%$ & $45.7 \%$ & $48.7 \%$ & $51.3 \%$ & $3.2 \%$ \\
\hline 6 & Textile & $45.5 \%$ & $38.5 \%$ & $61.5 \%$ & $37.1 \%$ & $47.5 \%$ & $52.5 \%$ & $1.7 \%$ \\
\hline 7 & Housing & $22.5 \%$ & $53.3 \%$ & $46.7 \%$ & $18.9 \%$ & $47.4 \%$ & $52.6 \%$ & $2.8 \%$ \\
\hline 8 & Mechanic industry & $34.9 \%$ & $53.7 \%$ & $46.3 \%$ & $36.6 \%$ & $46.7 \%$ & $53.3 \%$ & $3.0 \%$ \\
\hline 9 & Electric industry & $54.6 \%$ & $34.5 \%$ & $65.5 \%$ & $51.3 \%$ & $47.7 \%$ & $52.3 \%$ & $2.9 \%$ \\
\hline 10 & Metallurgy & $34.0 \%$ & $69.1 \%$ & $30.9 \%$ & $32.4 \%$ & $61.4 \%$ & $38.6 \%$ & $3.2 \%$ \\
\hline 11 & Health & $6.5 \%$ & $51.1 \%$ & $48.9 \%$ & $9.9 \%$ & $50.5 \%$ & $49.5 \%$ & $10.1 \%$ \\
\hline 12 & Construction & $0.0 \%$ & $0.0 \%$ & $0.0 \%$ & $0.0 \%$ & $0.0 \%$ & $0.0 \%$ & $7.1 \%$ \\
\hline 13 & Transports & $40.0 \%$ & $51.1 \%$ & $48.9 \%$ & $43.2 \%$ & $50.5 \%$ & $49.5 \%$ & $7.5 \%$ \\
\hline 14 & Hotels and restaurants & $0.0 \%$ & $0.0 \%$ & $0.0 \%$ & $0.0 \%$ & $0.0 \%$ & $0.0 \%$ & $2.3 \%$ \\
\hline 15 & Leisure & $17.3 \%$ & $72.7 \%$ & $27.3 \%$ & $18.8 \%$ & $59.2 \%$ & $40.8 \%$ & $7.7 \%$ \\
\hline 16 & Communications & $3.0 \%$ & $51.2 \%$ & $48.8 \%$ & $5.1 \%$ & $54.2 \%$ & $45.8 \%$ & $1.8 \%$ \\
\hline 17 & Public administration & $0.0 \%$ & $0.0 \%$ & $0.0 \%$ & $0.0 \%$ & $0.0 \%$ & $0.0 \%$ & $4.8 \%$ \\
\hline 18 & Non-financial services and R\&D & $3.8 \%$ & $51.2 \%$ & $48.8 \%$ & $3.6 \%$ & $54.2 \%$ & $45.8 \%$ & $21.9 \%$ \\
\hline 19 & Financial services & $2.8 \%$ & $51.2 \%$ & $48.8 \%$ & $3.9 \%$ & $54.2 \%$ & $45.8 \%$ & $5.0 \%$ \\
\hline
\end{tabular}

Source: Insee and OECD 
Table 12: Sectoral effects of a 10\% euro's depreciation on international trade

\begin{tabular}{llccc|ccc}
\hline & Exports & $\begin{array}{c}\text { Exports } \\
\text { (Eurozone) }\end{array}$ & $\begin{array}{c}\text { Exports (Rest } \\
\text { of the World) }\end{array}$ & Imports & $\begin{array}{c}\text { Imports } \\
\text { (Eurozone) }\end{array}$ & $\begin{array}{c}\text { Imports (Rest } \\
\text { of the World) }\end{array}$ \\
\hline 1 & Food & 2.2 & 0.9 & 4.9 & -5.3 & 2.6 & -18.7 \\
2 & Beverage & 3.4 & 1.0 & 5.0 & -6.2 & 0.6 & -14.2 \\
3 & Tobacco & 2.9 & 0.7 & 5.3 & -1.3 & 1.2 & -13.7 \\
4 & Energy & 2.4 & 1.0 & 4.1 & -7.4 & 6.0 & -12.3 \\
5 & Mineral products & 2.9 & 1.3 & 4.4 & -5.4 & 2.6 & -16.4 \\
6 & Textile & 3.6 & 1.8 & 5.1 & -9.3 & 6.8 & -19.4 \\
7 & Housing & 3.2 & 1.1 & 5.0 & -9.3 & -0.7 & -19.1 \\
8 & Mechanic industry & 3.1 & 1.2 & 4.8 & -11.0 & -0.6 & -23.1 \\
9 & Electric industry & 3.3 & 1.7 & 4.8 & -10.1 & 4.3 & -17.6 \\
10 & Metallurgy & 2.5 & 1.1 & 4.7 & -5.3 & 2.2 & -22.1 \\
11 & Health & 3.0 & 0.7 & 5.2 & -2.9 & 8.8 & -15.2 \\
12 & Construction & & & & & & -14.0 \\
13 & Transports & 2.6 & 1.2 & 4.1 & -6.6 & 0.5 & -18.7 \\
14 & Hotels et restaurants & & & & & & -17.1 \\
15 & Leisure & 2.6 & 0.8 & 5.1 & -3.7 & 1.9 & -19.0 \\
16 & Communications & 2.7 & 0.9 & 4.8 & -7.4 & 1.8 & -18.9 \\
17 & Public administration & & & & & & \\
18 & Non-financial services and R\&D & 2.7 & 0.7 & 5.0 & -7.6 & 3.3 & \\
19 & Financial services & 2.7 & 0.7 & 5.1 & -7.7 & 2.9 & \\
\hline
\end{tabular}

Table 13: Sectoral effects of a $10 \%$ euro's depreciation on macro variables

\begin{tabular}{|c|c|c|c|c|c|c|c|}
\hline & & Production & Labor & Capital & $\begin{array}{l}\text { Consumption } \\
\text { (MS sectors) }\end{array}$ & $\begin{array}{l}\text { Consumption } \\
\text { (CGE sectors) }\end{array}$ & Investments \\
\hline 1 & Food & 0.7 & 2.3 & 0.7 & -0.1 & & -10.9 \\
\hline 2 & Beverage & 0.1 & 2.0 & -0.1 & -1.8 & & \\
\hline 3 & Tobacco & 0.6 & 1.9 & -0.2 & 0.4 & & -10.6 \\
\hline 4 & Energy & 1.9 & 6.1 & 3.7 & & 0.1 & -12.9 \\
\hline 5 & Mineral products & 2.5 & 5.5 & 3.3 & & 0.3 & -11.5 \\
\hline 6 & Textile & 4.6 & 6.4 & 4.0 & 0.4 & & \\
\hline 7 & Housing & -1.2 & 0.9 & -1.4 & -1.5 & & -10.9 \\
\hline 8 & Mechanic industry & -1.3 & 1.1 & -1.2 & & 0.3 & -11.4 \\
\hline 9 & Electric industry & 3.0 & 5.5 & 3.1 & & 0.7 & -12.3 \\
\hline 10 & Metallurgy & 1.1 & 3.8 & 1.5 & & -1.2 & -11.1 \\
\hline 11 & Health & 0.7 & 2.2 & -0.1 & -0.7 & & -10.5 \\
\hline 12 & Construction & -9.2 & -6.7 & -8.9 & & 1.0 & -11.0 \\
\hline 13 & Transports & 0.5 & 5.3 & 2.5 & 0.1 & & -12.3 \\
\hline 14 & Hotels et restaurants & -0.4 & 1.9 & -0.4 & -2.8 & & \\
\hline 15 & Leisure & 0.4 & 2.3 & -0.1 & -0.2 & & -11.0 \\
\hline 16 & Communications & -0.4 & 2.0 & -0.3 & -0.3 & & \\
\hline 17 & Public administration & 0.6 & 2.2 & -0.1 & & 1.8 & \\
\hline 18 & Non-financial services and $R \& D$ & -0.9 & 1.0 & -1.3 & & 2.7 & -10.7 \\
\hline 19 & Financial services & -0.6 & 1.2 & -1.1 & 0.2 & & \\
\hline
\end{tabular}


Table 14: Sectoral effects of a $10 \%$ euro's depreciation on prices

\begin{tabular}{|c|c|c|c|c|c|c|}
\hline & & \multirow{2}{*}{ Domestic prices } & \multicolumn{3}{|c|}{ Foreign prices } & \multirow{2}{*}{ Tota } \\
\hline & & & Eurozone & Rest of the world & Total & \\
\hline 1 & Food & 0.0 & 0.7 & 10.0 & 3.8 & 0.4 \\
\hline 2 & Beverage & -0.2 & 0.6 & 10.0 & 4.8 & 0.2 \\
\hline 3 & Tobacco & -0.7 & -0.5 & 10.0 & 1.2 & -0.5 \\
\hline 4 & Energy & 1.5 & 2.5 & 10.0 & 7.8 & 1.9 \\
\hline 5 & Mineral products & 0.9 & 2.3 & 10.0 & 5.4 & 1.8 \\
\hline 6 & Textile & -0.5 & 2.0 & 10.0 & 6.6 & 2.3 \\
\hline 7 & Housing & -0.2 & 0.9 & 10.0 & 4.9 & 0.6 \\
\hline 8 & Mechanic industry & 0.2 & 1.5 & 10.0 & 5.1 & 1.4 \\
\hline 9 & Electric industry & 0.1 & 2.5 & 10.0 & 7.1 & 3.3 \\
\hline 10 & Metallurgy & 0.4 & 1.4 & 10.0 & 3.7 & 1.1 \\
\hline 11 & Health & -0.7 & -0.3 & 10.0 & 4.5 & -0.6 \\
\hline 12 & Construction & 0.3 & 0.8 & 10.0 & 0.0 & 0.3 \\
\hline 13 & Transports & 1.5 & 2.9 & 10.0 & 6.3 & 3.1 \\
\hline 14 & Hotels et restaurants & 0.0 & 0.5 & 10.0 & 0.0 & 0.0 \\
\hline 15 & Leisure & -0.4 & 0.1 & 10.0 & 2.6 & -0.2 \\
\hline 16 & Communications & 0.1 & 0.7 & 10.0 & 5.0 & 0.1 \\
\hline 17 & Public administration & -0.6 & -0.2 & 10.0 & 0.0 & -0.6 \\
\hline 18 & Non-financial services and $R \& D$ & -0.3 & 0.0 & 10.0 & 4.6 & -0.3 \\
\hline 19 & Financial services & -0.4 & -0.1 & 10.0 & 4.5 & -0.4 \\
\hline
\end{tabular}


Table 15: Microeconomic effects of a 10\% euro's depreciation on income inequality and income distribution

\begin{tabular}{lccc}
\hline & Baseline & Shock & variation \\
\hline Headcount ratio & $9.05 \%$ & $8.96 \%$ & $-1.0 \%$ \\
Poverty gap ratio & $2.53 \%$ & $2.50 \%$ & $-1.2 \%$ \\
Gini index & 0.2909 & 0.2899 & $-0.3 \%$ \\
10th percentile & 6867 & 6893 & $0.4 \%$ \\
50th percentile & 13363 & 13345 & $-0.1 \%$ \\
90th percentile & 24750 & 24677 & $-0.3 \%$ \\
90th / 10th perc. & 3.60 & 3.58 & $-0.7 \%$ \\
\hline
\end{tabular}

Table 16: Singles' labor supply reaction

\begin{tabular}{|c|c|c|c|c|c|c|}
\hline \multicolumn{7}{|c|}{ Prediction } \\
\hline & & 0 & 18 & 24 & 36 & Total \\
\hline \multirow{4}{*}{$\begin{array}{l}. \frac{.}{0} \\
\text { U] }\end{array}$} & 0 & 14.1 & 0.1 & 0.2 & 1.4 & 15.7 \\
\hline & 18 & 0.0 & 6.7 & 0.0 & 0.0 & 6.7 \\
\hline & 24 & 0.0 & 0.0 & 8.2 & 0.0 & 8.2 \\
\hline & 36 & 0.0 & 0.0 & 0.0 & 69.4 & 69.4 \\
\hline & Total & 14.1 & 6.7 & 8.4 & 70.8 & 100 \\
\hline
\end{tabular}


Table 17: Couples' labor supply reaction

\begin{tabular}{|c|c|c|c|c|c|c|c|c|c|c|}
\hline & \multicolumn{10}{|c|}{ Prediction } \\
\hline & & $0-0$ & $0-18$ & $0-24$ & $0-36$ & $36-0$ & $36-18$ & $36-24$ & $36-36$ & Total \\
\hline \multirow{9}{*}{$\begin{array}{l}\frac{\circlearrowright}{0} \\
\frac{0}{0}\end{array}$} & $0-0$ & 2.8 & 0.0 & 0.0 & 0.0 & 0.2 & 0.0 & 0.0 & 0.0 & 3.1 \\
\hline & $0-18$ & 0.0 & 0.8 & 0.0 & 0.0 & 0.0 & 0.1 & 0.0 & 0.0 & 0.9 \\
\hline & $0-24$ & 0.0 & 0.0 & 0.7 & 0.0 & 0.0 & 0.0 & 0.0 & 0.0 & 0.7 \\
\hline & $0-36$ & 0.0 & 0.0 & 0.0 & 2.5 & 0.0 & 0.0 & 0.0 & 0.4 & 2.9 \\
\hline & $36-0$ & 0.0 & 0.0 & 0.0 & 0.0 & 17.8 & 0.2 & 0.2 & 0.5 & 18.7 \\
\hline & $36-18$ & 0.0 & 0.0 & 0.0 & 0.0 & 0.0 & 9.9 & 0.0 & 0.0 & 9.9 \\
\hline & $36-24$ & 0.0 & 0.0 & 0.0 & 0.0 & 0.0 & 0.0 & 14.5 & 0.0 & 14.5 \\
\hline & $36-36$ & 0.0 & 0.0 & 0.0 & 0.0 & 0.0 & 0.0 & 0.0 & 49.3 & 49.4 \\
\hline & Total & 2.8 & 0.8 & 0.7 & 2.6 & 18.1 & 10.3 & 14.7 & 50.2 & 100 \\
\hline
\end{tabular}

Table 18: Percentage of winners, average percentage gain and percentage of losers and average loss

\begin{tabular}{lccccc}
\hline Family type & Winners & Gain & Losers & Loss & Net gain \\
\hline All families & $2.5 \%$ & $24.1 \%$ & $36.9 \%$ & $-1.1 \%$ & $0.2 \%$ \\
Poor & $8.7 \%$ & $34.2 \%$ & $11.6 \%$ & $-0.3 \%$ & $2.9 \%$ \\
Single males & $3.9 \%$ & $33.0 \%$ & $48.3 \%$ & $-1.1 \%$ & $0.8 \%$ \\
Single females & $2.8 \%$ & $14.3 \%$ & $29.2 \%$ & $-1.1 \%$ & $0.1 \%$ \\
Singles w/children & $10.2 \%$ & $18.2 \%$ & $63.6 \%$ & $-0.7 \%$ & $1.4 \%$ \\
Couples w/o children & $1.8 \%$ & $28.6 \%$ & $40.3 \%$ & $-1.1 \%$ & $0.1 \%$ \\
Couples w/1 child & $3.3 \%$ & $18.8 \%$ & $59.4 \%$ & $-1.2 \%$ & $-0.1 \%$ \\
Couples w/2 children & $2.9 \%$ & $37.9 \%$ & $65.5 \%$ & $-1.1 \%$ & $0.4 \%$ \\
Couples w/3 or more children & $2.3 \%$ & $20.2 \%$ & $61.3 \%$ & $-0.9 \%$ & $-0.1 \%$ \\
Elderly (more than 60) & $0.0 \%$ & $0.0 \%$ & $0.0 \%$ & $0.0 \%$ & $0.0 \%$ \\
\hline
\end{tabular}


Table 19: Consumption reaction

\begin{tabular}{|c|c|c|c|c|c|c|c|c|c|c|c|c|}
\hline Family type & Income & Food & Beverages & Tobacco & Clothing & Housing & Health & Transports & Comm. & Recreation & Hotels & Fin. serv. \\
\hline All families & $0.2 \%$ & $-1.8 \%$ & $0.4 \%$ & $-1.4 \%$ & $-0.7 \%$ & $0.2 \%$ & $-2.7 \%$ & $0.3 \%$ & $-0.2 \%$ & $-0.3 \%$ & $0.0 \%$ & $-0.1 \%$ \\
\hline Poor & $2.9 \%$ & $1.5 \%$ & $2.5 \%$ & $2.0 \%$ & $4.1 \%$ & $7.3 \%$ & $-0.3 \%$ & $10.6 \%$ & $4.7 \%$ & $2.9 \%$ & $2.1 \%$ & $2.2 \%$ \\
\hline Single males & $0.8 \%$ & $-1.6 \%$ & $1.5 \%$ & $0.1 \%$ & $-0.5 \%$ & $1.9 \%$ & $-1.9 \%$ & $0.7 \%$ & $1.9 \%$ & $0.2 \%$ & $0.4 \%$ & $0.1 \%$ \\
\hline Single females & $0.1 \%$ & $-1.8 \%$ & $0.1 \%$ & $-1.5 \%$ & $-0.7 \%$ & $0.1 \%$ & $-2.9 \%$ & $-0.4 \%$ & $-0.4 \%$ & $-0.5 \%$ & $0.0 \%$ & $-0.1 \%$ \\
\hline singles w/children & $1.4 \%$ & $-0.9 \%$ & $1.6 \%$ & $0.8 \%$ & $0.1 \%$ & $-0.6 \%$ & $-3.0 \%$ & $3.8 \%$ & $0.6 \%$ & $-0.2 \%$ & $0.4 \%$ & $0.5 \%$ \\
\hline Couples w/o children & $0.1 \%$ & $-2.0 \%$ & $0.3 \%$ & $-1.7 \%$ & $-0.8 \%$ & $-0.1 \%$ & $-2.8 \%$ & $-0.4 \%$ & $-0.6 \%$ & $-0.2 \%$ & $-0.2 \%$ & $-0.1 \%$ \\
\hline Couples w/1 child & $-0.1 \%$ & $-2.1 \%$ & $0.0 \%$ & $-2.0 \%$ & $-1.2 \%$ & $-0.6 \%$ & $-3.0 \%$ & $0.0 \%$ & $-0.7 \%$ & $-0.5 \%$ & $-0.5 \%$ & $-0.4 \%$ \\
\hline Couples w/2 children & $0.4 \%$ & $-1.8 \%$ & $0.1 \%$ & $-2.0 \%$ & $-0.2 \%$ & $1.1 \%$ & $-3.0 \%$ & $2.5 \%$ & $-0.4 \%$ & $-0.5 \%$ & $0.0 \%$ & $0.1 \%$ \\
\hline Couples w/3+ children & $-0.1 \%$ & $-2.1 \%$ & $-0.1 \%$ & $-1.5 \%$ & $-1.0 \%$ & $-0.3 \%$ & $-2.5 \%$ & $-0.7 \%$ & $-0.5 \%$ & $0.3 \%$ & $-0.1 \%$ & $-0.2 \%$ \\
\hline Elderly (more than 60) & $0.0 \%$ & $-1.7 \%$ & $0.3 \%$ & $-1.1 \%$ & $-0.6 \%$ & $0.0 \%$ & $-2.6 \%$ & $-0.3 \%$ & $-0.3 \%$ & $0.0 \%$ & $0.0 \%$ & $0.0 \%$ \\
\hline Price variation & & $0.2 \%$ & $-0.5 \%$ & $2.3 \%$ & $0.6 \%$ & $-0.6 \%$ & $3.1 \%$ & $0.0 \%$ & $-0.2 \%$ & $0.1 \%$ & $-0.4 \%$ & $0.4 \%$ \\
\hline
\end{tabular}


Table 20: Sensitivity analysis - Macro closures

\begin{tabular}{lllll}
\hline & & Base scenario & Neoclassical closure & Keynesian closure \\
\hline Real GDP & $(\%$ var $)$ & 0.6 & -0.6 & 4.6 \\
Unemployment rate & $(\%$ in p.p. $)$ & -1.8 & 0.0 & -7.9 \\
Labor & $(\%$ var $)$ & 1.9 & 0.0 & 8.6 \\
Capital & $(\%$ var $)$ & -0.8 & -0.9 & -0.8 \\
Real wage & $(\%$ var $)$ & -2.0 & -1.5 & -3.9 \\
Real rate of remuneration of capital & $(\%$ in p.p. $)$ & 0.0 & -0.1 & 0.2 \\
Consumer Price Index & $(\%$ var $)$ & 0.5 & 0.5 & 0.5 \\
\hline Private consumption & $(\%$ var $)$ & 0.1 & -0.5 & 2.0 \\
Investments & $(\%$ var $)$ & -11.2 & -14.4 & 0.0 \\
Government expenditure & $(\%$ var $)$ & 0.6 & -0.6 & 4.6 \\
Exports & $(\%$ var $)$ & 3.2 & 2.6 & 5.4 \\
Imports & $(\%$ var $)$ & -7.0 & -8.0 & -3.4 \\
\hline Private saving rate & $(\%$ in p.p. $)$ & 1.3 & 0.9 & 2.6 \\
Public deficit / GDP & $(\%$ in p.p. $)$ & 0.7 & 0.8 & 0.4 \\
Flow of domestic assets to RoW & $(\%$ var $)$ & 2.4 & 2.4 & -2.8 \\
Flow of foreign assets to France & $(\%$ var $)$ & -3.6 & -3.8 & \\
\hline
\end{tabular}


Table 21: Sensitivity analysis - Trade elasticities

\begin{tabular}{|c|c|c|c|c|}
\hline & & Base scenario & Elasticities x 0.5 & Elasticities x 1.5 \\
\hline Real GDP & $(\%$ var $)$ & 0.6 & 0.3 & 0.8 \\
\hline Unemployment rate & (\% in p.p.) & -1.8 & -1.3 & -2.2 \\
\hline Labor & $(\%$ var $)$ & 1.9 & 1.4 & 2.4 \\
\hline Capital & $(\%$ var $)$ & -0.8 & -0.8 & -0.8 \\
\hline Real wage & $(\%$ var $)$ & -2.0 & -2.0 & -2.0 \\
\hline Real rate of remuneration of capital & (\% in p.p.) & 0.0 & -0.1 & 0.0 \\
\hline Consumer Price Index & $(\%$ var $)$ & 0.5 & 0.5 & 0.5 \\
\hline Private consumption & $(\%$ var $)$ & 0.1 & -0.2 & 0.2 \\
\hline Investments & (\% var) & -11.2 & -7.2 & -14.9 \\
\hline Government expenditure & (\% var) & 0.6 & 0.3 & 0.8 \\
\hline Exports & $(\%$ var $)$ & 3.2 & 1.6 & 4.8 \\
\hline Imports & (\% var) & -7.0 & -5.2 & -8.7 \\
\hline Private saving rate & (\% in p.p.) & 1.3 & 1.2 & 1.3 \\
\hline Public deficit / GDP & (\% in p.p.) & 0.7 & 0.7 & 0.6 \\
\hline Flow of domestic assets to RoW & (\% var) & 2.4 & 2.4 & 2.4 \\
\hline Flow of foreign assets to France & (\% var) & -3.6 & -3.1 & -4.0 \\
\hline
\end{tabular}




\section{APPENDIX}

Technical description of the CGE model 


\section{A.1 Introduction}

In this technical document, we describe in details the CGE model that represents the macro component of our Micro-Macro simulation model. Our CGE model is a static and multisectoral model with two foreign zones: the Eurozone and the Rest of the World. The CGE model is built by using the French input-output data-set of 2006 provided by Insee which includes 118 sectors. We aggregate these sectors into 19 sectors, 11 of which correspond to the sectors used in the Microsimulation model concerning the consumption decisions. The construction of the SAM (Social Accounting Matrix), necessary to calibrate our CGE model, is completed by using national accounts concerning the government account and the balance of payments. Elasticities come from the GTAP model.

The sectors of the CGE model are indicated in Table A.1 which also indicates whether the consumption level is determined in the CGE model or in the Microsimulation (MS) model.

Table A.1: List of the sectors

\begin{tabular}{|c|c|c|c|}
\hline & & CGE & MS \\
\hline 1 Food & Agriculture, hunting, forestry, fishing. Food & & $\mathrm{x}$ \\
\hline 2 Beverage & Beverages & & $\mathrm{x}$ \\
\hline 3 Tobacco & Tobacco & & $\mathrm{x}$ \\
\hline 4 Energy & $\begin{array}{l}\text { Mining and quarrying. Coke, refined petroleum products and nuclear fuel. Production, } \\
\text { collection and distribution of electricity. Manufacture of gas; distribution of gaseous fuels } \\
\text { through mains. Steam and hot water supply. Collection, purification and distribution of water }\end{array}$ & $\mathrm{x}$ & \\
\hline 5 Mineral products & $\begin{array}{l}\text { Chemicals excluding pharmaceuticals. Rubber and plastics products. Other non-metallic } \\
\text { mineral products }\end{array}$ & $\mathrm{x}$ & \\
\hline 6 Textile & Textiles, textile products, leather and footwear & & $\mathrm{x}$ \\
\hline 7 Housing & Wood and products of wood and cork & & $\mathrm{x}$ \\
\hline 8 Mechanic industry & Machinery and equipment, nec & $\mathrm{x}$ & \\
\hline 9 Electric industry & $\begin{array}{l}\text { Office, accounting and computing machinery. Electrical machinery and apparatus. Medical, } \\
\text { precision and optical instruments }\end{array}$ & $\mathrm{x}$ & \\
\hline 10 Metallurgy & $\begin{array}{l}\text { Iron and steel. Non-ferrous metals. Fabricated metal products, except machinery and } \\
\text { equipment }\end{array}$ & $\mathrm{x}$ & \\
\hline 11 Health & Health and social work. Pharmaceuticals. Education & & $\mathrm{x}$ \\
\hline 12 Construction & Construction & $\mathrm{x}$ & \\
\hline 13 Transports & $\begin{array}{l}\text { Motor vehicles, trailers and semi-trailers. Building and repairing of ships and boats. Aircraft } \\
\text { and spacecraft. Railroad equipment and transport equip nec. Manufacturing nec; recycling. } \\
\text { Land transport; transport via pipelines. Water transport. Air transport. Supporting and } \\
\text { auxiliary transport activities. Activities of travel agencies }\end{array}$ & & $\mathrm{x}$ \\
\hline 14 Hotels et restaurants & Hotels and restaurants & & $\mathrm{x}$ \\
\hline 15 Leisure & $\begin{array}{l}\text { Pulp, paper, paper products, printing and publishing. Radio, television and communication } \\
\text { equipment. Other community, social and personal services. Private households with } \\
\text { employed persons and extra-territorial organisations and bodies }\end{array}$ & & $\mathrm{x}$ \\
\hline 16 Communications & Post and telecommunications & & $\mathrm{x}$ \\
\hline 17 Public administration & Public admin. and defence; compulsory social security & $\mathrm{x}$ & \\
\hline 18 Non-financial services and R\&D & $\begin{array}{l}\text { Real estate activities. Renting of machinery and equipment. Computer and related activities, } \\
\text { Research and development. Other Business Activities }\end{array}$ & $\mathrm{x}$ & \\
\hline 19 Financial services & Finance and insurance & & $\mathrm{x}$ \\
\hline
\end{tabular}




\section{A.2 The equations of the model}

\section{A.2.1 Sectors}

For each sector, we use a multi-stage CES production function. In the first stage, the production level of a sector $i\left(Y_{i}\right)$ depends on the total quantity of intermediate goods $\left(Z_{i}\right)$, labor $\left(L_{i}\right)$ and capital $\left(K_{i}\right)$ used:

$$
Y_{i}=\left[\left(\alpha_{Z, i}\right)^{\frac{1}{\sigma_{i}}} \cdot Z_{i}^{\rho_{i}}+\left(\alpha_{L, i}\right)^{\frac{1}{\sigma_{i}}} \cdot L_{i}^{\rho_{i}}+\left(\alpha_{K, i}\right)^{\frac{1}{\sigma_{i}}} \cdot K_{i}^{\rho_{i}}\right]^{\frac{1}{\rho_{i}}}
$$

The first order conditions in order to maximize profit given the technological constraint are:

$$
\begin{aligned}
Z_{i} & =\alpha_{Z, i} \cdot\left[\frac{P_{i}^{h} \cdot\left(1-\tau_{y, i}\right)}{P Z_{i}}\right]^{\sigma_{i}} \cdot Y_{i} \\
L_{i} & =\alpha_{L, i} \cdot\left[\frac{P_{i}^{h} \cdot\left(1-\tau_{y, i}\right)}{w \cdot\left(1+\cot _{\text {patr }}\right)}\right]^{\sigma_{i}} \cdot Y_{i} \\
K_{i} & =\alpha_{K, i} \cdot\left[\frac{P_{i}^{h} \cdot\left(1-\tau_{y, i}\right)}{r+\delta}\right]^{\sigma_{i}} \cdot Y_{i} \\
P_{i}^{h} \cdot\left(1-\tau_{y, i}\right) \cdot Y_{i} & =P Z_{i} \cdot Z_{i}+w \cdot\left(1+\cot _{\text {patr }}\right) \cdot L_{i}+(r+\delta) \cdot K_{i}
\end{aligned}
$$

Equations (1), (2), (3) and (4) determine $Z_{i}, L_{i}, K_{i}$ and $Y_{i} . P_{i}^{h}$ is the home price of the good produced by sector $i . w$ and $r+\delta$ represent respectively the equilibrium remuneration of one unit of labor and capital that are both supposed to be unique given the hypothesis of perfect mobility of the production factors across sectors. The parameters $\cot _{\text {patr }}$ and $\tau_{y, i}$ represent respectively the social contributions rate paid by the employers and the tax rate on production. $P_{i}^{h} \cdot\left(1-\tau_{y, i}\right)$ represents the average net price on sales earned by the firm. $w \cdot\left(1+\cot _{\text {patr }}\right)$ represents the total cost paid by a firm to hire one unit of labor. $P Z_{i}$ represents the aggregate price of intermediate goods used by sector $i$, defined later.

In the second stage, each sector $i$ chooses the repartition of the total intermediate good into different intermediate goods sold by $j\left(Z_{j i}\right)$. The choice is made in order to minimize the total cost and to respect the following constraint:

$$
Z_{i}=\left[\sum_{j}\left(\alpha_{Z_{j i}}\right)^{\frac{1}{\sigma Z_{i}}} \cdot Z_{j i}^{\rho Z_{i}}\right]^{\frac{1}{\rho Z_{i}}}
$$

The first order conditions are:

$$
\begin{aligned}
Z_{j i} & =\alpha_{Z_{j i}} \cdot\left[\frac{P Z_{i}}{P Z_{j i}}\right]^{\sigma Z_{i}} \cdot Z_{i} \\
P Z_{i} \cdot Z_{i} & =\sum_{j} P Z_{j i} \cdot Z_{j i}
\end{aligned}
$$

These equations determine respectively $Z_{j i}$ and $P Z_{i}$.

$P Z_{j i}$ is the average price of the intermediate goods of type $j$ that sector $i$ buys, defined later.

$Z_{j i}$ represents the quantity of good $j$ that sector $i$ buys. This quantity can be produced in the domestic market $(h)$ or abroad $(f)$. The repartition is made in order to minimize the total cost and to respect the following constraint: 


$$
Z_{j i}=\left[\left(\alpha_{j i}^{h}\right)^{\frac{1}{\sigma Z_{j i}}} \cdot\left(Z_{j i}^{h}\right)^{\rho Z_{j i}}+\left(\alpha_{j i}^{f}\right)^{\frac{1}{\sigma Z_{j i}}} \cdot\left(Z_{j i}^{f}\right)^{\rho Z_{j i}}\right]^{\frac{1}{\rho Z_{j i}}}
$$

The first order conditions are:

$$
\begin{aligned}
Z_{j i}^{h} & =\alpha_{j i}^{h} \cdot\left[\frac{P Z_{j i}}{P_{j}^{h}}\right]^{\sigma Z_{j i}} \cdot Z_{j i} \\
Z_{j i}^{f} & =\alpha_{j i}^{f} \cdot\left[\frac{P Z_{j i}}{P Z_{j}^{f}}\right]^{\sigma Z_{j i}} \cdot Z_{j i} \\
P Z_{j i} \cdot Z_{j i} & =P_{j}^{h} \cdot Z_{j i}^{h}+P Z_{j i}^{f} \cdot Z_{j i}^{f}
\end{aligned}
$$

These equations determine $Z_{j i}^{h}, Z_{j i}^{f}$ and $P Z_{j i}$.

$P Z_{j i}$ is the average price of the intermediate goods of type $j$ that sector $i$ buys computed as the weighted average between the equilibrium domestic price $\left(P_{j}^{h}\right)$ and the foreign price $\left(P Z_{j i}^{f}\right)$, defined later.

$Z_{j i}^{f}$ represents the quantity of good $j$ that sector $i$ buys abroad. This quantity can be produced in the Eurozone $(E z)$ or in the rest of the world (Row). The repartition is made in order to minimize the total cost and to respect the following constraint:

$$
Z_{j i}^{f}=\left[\left(\alpha_{j i}^{E z}\right)^{\frac{1}{\sigma Z_{j i}^{f}}} \cdot\left(Z_{j i}^{E z}\right)^{\rho Z_{j i}^{f}}+\left(\alpha_{j i}^{R o w}\right)^{\frac{1}{\sigma Z_{j i}^{f}}} \cdot\left(Z_{j i}^{R o w}\right)^{\rho Z_{j i}^{f}}\right]^{\frac{1}{\rho Z_{j i}^{f}}}
$$

The first order conditions are:

$$
\begin{aligned}
Z_{j i}^{E z} & =\alpha_{j i}^{E z} \cdot\left[\frac{P Z_{j i}^{f}}{P_{j}^{E z}}\right]^{\sigma Z_{j i}^{f}} \cdot Z_{j i}^{f} \\
Z_{j i}^{\text {Row }} & =\alpha_{j i}^{\text {Row }} \cdot\left[\frac{P Z_{j i}^{f}}{P_{j}^{R o w} \cdot \varepsilon}\right]^{\sigma Z_{j i}^{f}} \cdot Z_{j i}^{f} \\
P Z_{j i}^{f} \cdot Z_{j i}^{f} & =P_{j}^{E z} \cdot Z_{j i}^{E z}+P_{j}^{R o w} \cdot \varepsilon \cdot Z_{j i}^{\text {Row }}
\end{aligned}
$$

These equations determine $Z_{j i}^{E z}, Z_{j i}^{R o w}$ and $P Z_{j i}^{f}$.

$P Z_{j i}^{f}$ represents the average price of the intermediate goods of type $j$ that sector $i$ buys abroad which is computed as the weighted average between the price in the Eurozone $P_{j}^{E z}$ and the world price expressed in euros $P_{j}^{R o w} \cdot \varepsilon$. In particular, $\varepsilon$ is the nominal exchange rate that is assumed to be exogenous (while financial flows are endogenously determined in order to equilibrate the balance of payments) and is used to simulate the macroeconomic shock in our model. The world price of good $j$ expressed in foreign currency $P_{j}^{\text {Row }}$ is exogenous, while the price in the Eurozone $P_{j}^{E z}$ is treated as endogenous since it is reasonable to assume that euro's depreciation would affect prices in the whole Eurozone. For each sector $j$, the price in the Eurozone $P_{j}^{E z}$ is computed as a weighted average between a domestic price in the Eurozone (which is assumed to vary in the same proportion as the domestic price in France) and the world price expressed in euros. 


\section{A.2.2 Exports}

A fraction of the production is sold in the domestic market and the complementary fraction is exported. Goods that are exported are supposed to be identical to those sold in the domestic market, implying that the selling price $P_{i}^{h}$ is the same.

Exports are defined by a decreasing function of the relative price, i.e. the ratio between the foreign price expressed in Euros and the domestic price. Exports towards the Eurozone $\left(E_{i}^{E z}\right)$ and the rest of the world $\left(E_{i}^{\text {Row }}\right)$ are given by :

$$
\begin{aligned}
E_{i}^{E z} & =\alpha_{i}^{E z} \cdot\left[\frac{P_{i}^{E z}}{P_{i}^{h}}\right]^{\sigma E_{i}} \\
E_{i}^{\text {Row }} & =\alpha_{i}^{\text {Row }} \cdot\left[\frac{P_{i}^{\text {Row }} \cdot \varepsilon}{P_{i}^{h}}\right]^{\sigma E_{i}}
\end{aligned}
$$

These equations determine respectively $E_{i}^{E z}$ and $E_{i}^{\text {Row }}$.

In particular, as we have already said, prices in the Eurozone are assumed to be endogenous in order to take into account that Euro's devaluation represents a shock affecting the whole Eurozone. Consequently, it is reasonable to presume that real GDP in the Eurozone is affected by the shock as in France. For this reason, the terms $\alpha_{i}^{E z}$ are assumed to be endogenous and to vary in the same proportion as the French real GDP.

\section{A.2.3 Consumption}

In our Micro-Macro simulation model, the labor supply depends on the quantity of labor that people want to supply (that is determined by the Microsimulation model) and on the unemployment rate (that can be exogenous or endogenous depending on the macro closure used in the CGE model). Thus, in the CGE model, utility does not depend on leisure but only on consumption of goods and services.

In particular, the consumption level for 11 (over 19) sectors is determined by the Microsimulation model. Therefore, in the CGE model, the representative agent has to decide the optimal level of consumption for the 8 "CGE sectors" ( $\left.i^{\text {cge }}=4,5,8,9,10,12,17,18\right)$.

First, the representative agent determines the level of total consumption for the "CGE goods" $\left(C^{c g e}\right)$. We assume that the value of total consumption for the "CGE goods" is equal to a fraction of the total disposable income:

$$
P C^{c g e} \cdot C^{c g e}=\alpha_{C} \cdot Y_{\text {disp }}
$$

This equation determines $C^{c g e}$.

$P C^{c g e}$ is the price index of the "CGE goods", while $Y_{\text {disp }}$ indicates the disposable income, both defined later.

Starting from the total consumption for the "CGE goods", the representative agent chooses, for each "CGE goods" $i$, the optimal quantity $C_{i}^{c g e}$, by maximizing the following CES utility function:

$$
C^{c g e}=\left[\sum_{i=i_{c g e}}\left(\alpha_{C_{i}^{c g e}}\right)^{\frac{1}{\sigma C}} \cdot\left(C_{i}^{c g e}\right)^{\rho C}\right]^{\frac{1}{\rho C}}
$$


The first order conditions are:

$$
\begin{aligned}
C_{i}^{c g e} & =\alpha_{C_{i}^{c g e}} \cdot\left[\frac{P C}{P C_{i}^{c g e}}\right]^{\sigma C} \cdot C \\
P C^{c g e} \cdot C^{c g e} & =\sum_{i=i_{c g e}} P C_{i}^{c g e} \cdot C_{i}^{c g e}
\end{aligned}
$$

The previous equations determine respectively the consumption level and the price index for the "CGE goods" $\left(C_{i}^{c g e}\right.$ and $\left.P C^{c g e}\right)$. The consumption level for the "microsimulation goods" $\left(C_{i}^{m s}\right)$ is fixed at the level determined by the Microsimulation model.

Households can consume, for each sector $i$, domestic goods $C_{i}^{h}$ and foreign goods $C_{i}^{f}$ and the optimal repartition, is chosen in order to minimize the total cost and to respect the following constraint:

$$
C_{i}=\left[\left(\alpha_{C_{i}}^{h}\right)^{\frac{1}{\sigma C_{i}}} \cdot\left(C_{i}^{h}\right)^{\rho C_{i}}+\left(\alpha_{C_{i}}^{f}\right)^{\frac{1}{\sigma C_{i}}} \cdot\left(C_{i}^{f}\right)^{\rho C_{i}}\right]^{\frac{1}{\rho C_{i}}}
$$

The first order conditions are:

$$
\begin{aligned}
C_{i}^{h} & =\alpha_{C_{i}}^{h} \cdot\left[\frac{P C_{i}}{P_{i}^{h} \cdot\left(1+\tau_{V A T_{i}}\right)}\right]^{\sigma C_{i}} \cdot C_{i} \\
C_{i}^{f} & =\alpha_{C_{i}}^{f} \cdot\left[\frac{P C_{i}}{P C_{i}^{f}}\right]^{\sigma C_{i}} \cdot C_{i} \\
P C_{i} \cdot C_{i} & =P_{i}^{h} \cdot\left(1+\tau_{V A T_{i}}\right) \cdot C_{i}^{h}+P C_{i}^{f} \cdot C_{i}^{f}
\end{aligned}
$$

These equations determine $C_{i}^{h}, C_{i}^{f}$ and $P C_{i}$.

In particular, $P C_{i}$ represents the average consumption price of good $i$, computed as the average between the domestic consumption price $P_{i}^{h} \cdot\left(1+\tau_{V A T_{i}}\right)$ and the foreign consumption price $P C_{i}^{f}$, defined later. The parameter $\tau_{V A T_{i}}$ indicates the VAT rate in sector $i$.

Households can consume foreign goods coming from the Eurozone $C_{i}^{E z}$ and from the rest of the world $C_{i}^{\text {Row }}$. The optimal composition is chosen in order to minimize the total cost and to respect the following constraint:

$$
C_{i}^{f}=\left[\left(\alpha_{C_{i}}^{E z}\right)^{\frac{1}{\sigma C_{i}^{f}}} \cdot\left(C_{i}^{E z}\right)^{\rho C_{i}^{f}}+\left(\alpha_{C_{i}}^{R o w}\right)^{\frac{1}{\sigma C_{i}^{f}}} \cdot\left(C_{i}^{R o w}\right)^{\rho C_{i}^{f}}\right]^{\frac{1}{\rho C_{i}^{f}}}
$$

The first order conditions are:

$$
\begin{aligned}
C_{i}^{E z} & =\alpha_{C_{i}}^{E z} \cdot\left(\frac{P C_{i}^{f}}{P_{i}^{E z} \cdot\left(1+\tau_{V A T_{i}}\right)}\right)^{\sigma C_{i}^{f}} \cdot C_{i}^{f} \\
C_{i}^{\text {Row }} & =\alpha_{C_{i}}^{\text {Row }} \cdot\left(\frac{P C_{i}^{f}}{P_{i}^{\text {Row }} \cdot \varepsilon \cdot\left(1+\tau_{V A T_{i}}\right)}\right)^{\sigma C_{i}^{f}} \cdot C_{i}^{f} \\
P C_{i}^{f} \cdot C_{i}^{f} & =P_{i}^{E z} \cdot\left(1+\tau_{V A T_{i}}\right) \cdot C_{i}^{E z}+P_{i}^{\text {Row }} \cdot \varepsilon \cdot\left(1+\tau_{V A T_{i}}\right) \cdot C_{i}^{\text {Row }}
\end{aligned}
$$

These equations determine $C_{i}^{E z}, C_{i}^{R o w}$ and $P C_{i}^{f}$.

In particular, $P C_{i}^{f}$ represents the average foreign consumption price of good $i$ computed as the average 
between the (endogenous) Eurozone consumption price $P_{i}^{E z} \cdot\left(1+\tau_{V A T_{i}}\right)$ and the (exogenous) world consumption price $P_{i}^{\text {Row }} \cdot \varepsilon \cdot\left(1+\tau_{V A T_{i}}\right)$.

\section{A.2.4 Investment}

The repartition of the aggregate investment $I$, which is defined later, into the sectors of our CGE model $\left(I_{i}\right)$ is made in order to minimize the total cost and to respect the following constraint:

$$
I=\left[\sum_{i}\left(\alpha_{I_{i}}\right)^{\frac{1}{\sigma I}} \cdot\left(I_{i}\right)^{\rho I}\right]^{\frac{1}{\rho I}}
$$

The first order conditions are:

$$
\begin{aligned}
I_{i} & =\alpha_{I_{i}} \cdot\left[\frac{P I}{P I_{i}}\right]^{\sigma I} \cdot I \\
P I \cdot I & =\sum_{i} P I_{i} \cdot I_{i}
\end{aligned}
$$

These equations determine $I_{i}$ and the price index of investments $P I$.

In particular, investment goods can come from the domestic market, indicated respectively $I_{i}^{h}$ and $I_{i}^{f}$. The optimal repartition is made by minimizing the total cost and by respecting the following constraint:

$$
I_{i}=\left[\left(\alpha_{I_{i}}^{h}\right)^{\frac{1}{\sigma I_{i}}} \cdot\left(I_{i}^{h}\right)^{\rho I_{i}}+\left(\alpha_{I_{i}}^{f}\right)^{\frac{1}{\sigma I_{i}}} \cdot\left(I_{i}^{f}\right)^{\rho I_{i}}\right]^{\frac{1}{\rho I_{i}}}
$$

The first order conditions are:

$$
\begin{aligned}
I_{i}^{h} & =\alpha_{I_{i}}^{h} \cdot\left[\frac{P I_{i}}{P_{i}^{h} \cdot\left(1+\tau_{V A T_{i}}\right)}\right]^{\sigma I_{i}} \cdot I_{i} \\
I_{i}^{f} & =\alpha_{I_{i}}^{f} \cdot\left[\frac{P I_{i}}{P I_{i}^{f}}\right]^{\sigma I_{i}} \cdot I_{i} \\
P I_{i} \cdot I_{i} & =P_{i}^{h} \cdot\left(1+\tau_{V A T_{i}}\right) \cdot I_{i}^{h}+P I_{i}^{f} \cdot I_{i}^{f}
\end{aligned}
$$

These equations determine $I_{i}^{h}, I_{i}^{f}$ and $P I_{i}$.

In particular, $P I_{i}$ represents the average investment price of good $i$, computed as the average between the domestic investment price $P_{i}^{h} \cdot\left(1+\tau_{V A T_{i}}\right)$ and the foreign investment price $P I_{i}^{f}$, defined later.

Foreign investment goods can come from the Eurozone and from the rest of the world, indicated respectively $I_{i}^{E z}$ and $I_{i}^{R o w}$. The optimal repartition is chosen by minimizing the total cost and by respecting the following constraint:

$$
I_{i}^{f}=\left[\left(\alpha_{I_{i}}^{E z}\right)^{\frac{1}{\sigma I_{i}^{f}}} \cdot\left(I_{i}^{E z}\right)^{\rho I_{i}^{f}}+\left(\alpha_{I_{i}}^{R o w}\right)^{\frac{1}{\sigma I_{i}^{f}}} \cdot\left(I_{i}^{R o w}\right)^{\rho I_{i}^{f}}\right]^{\frac{1}{\rho I_{i}^{f}}}
$$

The first order conditions are: 


$$
\begin{aligned}
I_{i}^{E z} & =\alpha_{I_{i}}^{E z} \cdot\left[\frac{P I_{i}^{f}}{P_{i}^{E z} \cdot\left(1+\tau_{V A T_{i}}\right)}\right]^{\sigma I_{i}^{f}} \cdot I_{i}^{f} \\
I_{i}^{\text {Row }} & =\alpha_{I_{i}}^{\text {Row }} \cdot\left[\frac{P I_{i}^{f}}{P_{i}^{\text {Row }} \cdot \varepsilon \cdot\left(1+\tau_{V A T_{i}}\right)}\right]^{\sigma I_{i}^{f}} \cdot I_{i}^{f} \\
P I_{i}^{f} \cdot I_{i}^{f} & =P_{i}^{E z} \cdot\left(1+\tau_{V A T_{i}}\right) \cdot I_{i}^{E z}+P_{i}^{R o w} \cdot \varepsilon \cdot\left(1+\tau_{V A T_{i}}\right) \cdot I_{i}^{\text {Row }}
\end{aligned}
$$

These equations determine $I_{i}^{E z}, I_{i}^{R o w}$ and $P_{I, i}^{f}$.

In particular, $P_{I, i}^{f}$ represents the average foreign investment price of good $i$, computed as the average between the (endogenous) Eurozone price $P_{i}^{E z} \cdot\left(1+\tau_{V A T_{i}}\right)$ and the (exogenous) world price $P_{i}^{R o w} \cdot \varepsilon \cdot(1+$ $\left.\tau_{V A T_{i}}\right)$.

\section{A.2.5 Government expenditure}

The total government expenditure, denoted by $G$, is determined in the model by assuming that the ratio with respect to real GDP is constant:

$$
\frac{G}{G D P_{\text {real }}}=\text { const }_{G}
$$

This equation determines $G$, while const $_{G}$ is calibrated in order to reproduce the 2006 value of the total government expenditure.

The repartition of the total government expenditure $(G)$ into different sectors is made in order to minimize the total cost and to respect the following constraint:

$$
G=\left[\sum_{i}\left(\alpha_{G_{i}}\right)^{\frac{1}{\sigma G}} \cdot\left(G_{i}\right)^{\rho G}\right]^{\frac{1}{\rho G}}
$$

The first order conditions are:

$$
\begin{aligned}
G_{i} & =\alpha_{G_{i}} \cdot\left[\frac{P G}{P G_{i}}\right]^{\sigma G} \cdot G \\
P G \cdot G & =\sum_{i} P G_{i} \cdot G_{i}
\end{aligned}
$$

These equations determine $G_{i}$ and the government price index $P G$.

In particular, the government can consume domestic and foreign goods. The optimal repartition is made by minimizing the total cost and by respecting the following constraint:

$$
G_{i}=\left[\left(\alpha_{G_{i}}^{h}\right)^{\frac{1}{\sigma G_{i}}} \cdot\left(G_{i}^{h}\right)^{\rho G_{i}}+\left(\alpha_{G_{i}}^{f}\right)^{\frac{1}{\sigma G_{i}}} \cdot\left(G_{i}^{f}\right)^{\rho G_{i}}\right]^{\frac{1}{\rho G_{i}}}
$$

The first order conditions are: 


$$
\begin{aligned}
G_{i}^{h} & =\alpha_{G_{i}}^{h} \cdot\left[\frac{P G_{i}}{P_{i}^{h} \cdot\left(1+\tau_{V A T_{i}}\right)}\right]^{\sigma G_{i}} \cdot G_{i} \\
G_{i}^{f} & =\alpha_{G_{i}}^{f} \cdot\left[\frac{P G_{i}}{P G_{i}^{f}}\right]^{\sigma G_{i}} \cdot G_{i} \\
P G_{i} \cdot G_{i} & =P_{i}^{h} \cdot\left(1+\tau_{V A T_{i}}\right) \cdot G_{i}^{h}+P G_{i}^{f} \cdot G_{i}^{f}
\end{aligned}
$$

These equations determine $G_{i}^{h}, G_{i}^{f}$ and $P G_{i}$.

In particular, $P G_{i}$ represents the average price of good $i$, computed as the average between the domestic price $P_{i}^{h} \cdot\left(1+\tau_{V A T_{i}}\right)$ and the foreign price $P G_{i}^{f}$, defined later.

Foreign goods demanded by the government can come from the Eurozone and from the rest of the world. The optimal repartition is chosen by minimizing the total cost and by respecting the following constraint:

$$
G_{i}^{f}=\left[\left(\alpha_{G_{i}}^{E z}\right)^{\frac{1}{\sigma G_{i}^{f}}} \cdot\left(G_{i}^{E z}\right)^{\rho G_{i}^{f}}+\left(\alpha_{G_{i}}^{R o w}\right)^{\frac{1}{\sigma G_{i}^{f}}} \cdot\left(G_{i}^{R o w}\right)^{\rho G_{i}^{f}}\right]^{\frac{1}{\rho G_{i}^{f}}}
$$

The first order conditions are:

$$
\begin{aligned}
G_{i}^{E z} & =\alpha_{i}^{E z} \cdot\left[\frac{P G_{i}^{f}}{P_{i}^{E z} \cdot\left(1+\tau_{V A T_{i}}\right)}\right]^{\sigma G_{i}^{f}} \cdot G_{i}^{f} \\
G_{i}^{\text {Row }} & =\alpha_{i}^{\text {Row }} \cdot\left[\frac{P G_{i}^{f}}{P_{i}^{\text {Row }} \cdot \varepsilon \cdot\left(1+\tau_{V A T_{i}}\right)}\right]^{\sigma G_{i}^{f}} \cdot G_{i}^{f} \\
P G_{i}^{f} \cdot G_{i}^{f} & =P_{i}^{E z} \cdot\left(1+\tau_{V A T_{i}}\right) \cdot G_{i}^{E z}+P_{i}^{R o w} \cdot \varepsilon \cdot\left(1+\tau_{V A T_{i}}\right) \cdot G_{i}^{\text {Row }}
\end{aligned}
$$

These equations determine $G_{i}^{E z}, G_{i}^{R o w}$ and $P G_{i}^{f}$.

In particular, $P G_{i}^{f}$ represents the average foreign price of good $i$, computed as the average between the (endogenous) Eurozone price $P_{i}^{E z} \cdot\left(1+\tau_{V A T_{i}}\right)$ and the (exogenous) world price $P_{i}^{R o w} \cdot \varepsilon \cdot\left(1+\tau_{V A T_{i}}\right)$.

\section{A.2.6 Domestic demand of goods and services}

For each sector $i$, the total domestic demand in the domestic market $\left(X_{i}^{h}\right)$ is given by the sum of domestic intermediate goods, consumption (private and public) and investments:

$$
X_{i}^{h}=\sum_{j} Z_{i j}^{h}+C_{i}^{h}+I_{i}^{h}+G_{i}^{h}
$$

This equation determines $X_{i}^{h}$.

\section{A.2.7 Imports of goods and services}

For each sector $i$, the total imports from the Eurozone and from the rest of the world are given by: 


$$
\begin{aligned}
M_{i}^{E z} & =\sum_{j} Z_{i j}^{E z}+C_{i}^{E z}+I_{i}^{E z}+G_{i}^{E z} \\
M_{i}^{\text {Row }} & =\sum_{j} Z_{i j}^{\text {Row }}+C_{i}^{\text {Row }}+I_{i}^{\text {Row }}+G_{i}^{\text {Row }}
\end{aligned}
$$

These equations determine $M_{i}^{E z}$ and $M_{i}^{R o w}$.

\section{A.2.8 Household budget constraint}

First, we define the gross income perceived by the representative agent as the sum of labor and capital incomes and transfers from the government:

$$
\begin{aligned}
Y_{\text {gross }} & =w \cdot\left(1-\cot _{\text {empl }}\right) \cdot L_{F r-F r} \cdot(1-u)+w^{E z} \cdot L_{F r-E z} \\
& +r \cdot P I \cdot A_{F r-F r}+r^{R o w} \cdot \varepsilon \cdot A_{F r-R o w}+\Gamma_{m s}+\Gamma
\end{aligned}
$$

The first component in the RHS represents the labor incomes earned in France which depend on the domestic wage $w$, the contribution rate paid by the employees $\cot _{e m p l}$ and the number of French people who work in France $L_{F r-F r} \cdot(1-u)$. The latter variable depends on the quantity of labor that people decide to supply $L_{F r-F r}$ that is fixed at the level determined in the Microsimulation model, and on the unemployment rate $u$ which can be exogenous or endogenous in the CGE model according to the macro closure rule that is chosen. The second component is the labor incomes earned abroad which depend on the exogenous foreign wage rate $w^{E z}$ and the exogenous number of French people who work abroad $L_{F r-E z}$. We assume that French people who work abroad work in the Eurozone. The capital incomes earned in France (third component) depend on the domestic interest rate $r$ and the value of assets owned by French people in France $A_{F r-F r}$, while the capital incomes earned abroad (fourth component) depend on the exogenous world interest rate $r^{R o w}$, the exogenous exchange rate $\varepsilon$ and the value of assets owned by French people in the rest of the world $A_{F r-R o w}$. The last two elements in the RHS represent the transfers paid by the government. We consider two types of transfers: (i) $\Gamma_{m s}$ represents transfers that affect the labor incomes (and thus the labor market choices), the value of which is fixed at the level determined in the Microsimulation model. ${ }^{19}$ (ii) $\Gamma$ represents other (exogenous) transfers from the government that do not affect individual labor choices (that include, for example, pension benefits).

The disposable income is computed as the difference between the gross income and taxes on labor and capital incomes:

$$
Y_{\text {disp }}=Y_{\text {gross }}-\operatorname{Tax}_{l a b}-\tau_{c a p} \cdot r \cdot P I \cdot A_{F r-F r}
$$

In particular the value of the taxes on labor incomes $\left(\operatorname{Tax}_{l a b}\right)$ is fixed at the level determined in the Microsimulation model. $\tau_{c a p}$ is the tax rate on capital incomes.

The budget constraint states that the difference between the disposable income and the consumption of goods and services is saved:

\footnotetext{
${ }^{19} \Gamma_{m s}$ includes Allocations familiales, Allocations parents isolés, Allocation de rentrée scolaire, Complément familial, Aide au logement, Prestation d'accueil du jeune enfant, Prime à la naissance, Allocation de base, Complément de libre choix d'activité, Allocation parentale d'éducation, Aide assistante maternelle, Allocations pour jeune enfant, Prime pour l'emploi, Revenu minimum d'insertion, Minimum vieillesse.
} 


$$
S_{H}=Y_{\text {disp }}-\sum_{i} P C_{i} \cdot C_{i}
$$

This equation determines private savings $S_{H}$, implying that the propensity to save is endogenous. ${ }^{20}$

\section{A.2.9 Government budget constraint}

Government savings are given by the difference between revenues (that come from direct and indirect taxes and social contributions) and expenditures (represented by the total public expenditure, interests on the public debt $B$ and transfers to households):

$$
\begin{aligned}
S_{G} & =\sum_{i} \tau_{y, i} \cdot P_{i}^{h} \cdot Y_{i} \\
& +\sum_{i} \tau_{V A T_{i}} \cdot\left[P_{i}^{h} \cdot\left(C_{i}^{h}+I_{i}^{h}+G_{i}^{h}\right)+P_{i}^{E z} \cdot\left(C_{i}^{E z}+I_{i}^{E z}+G_{i}^{E z}\right)+P_{i}^{\text {Row }} \cdot \varepsilon \cdot\left(C_{i}^{\text {Row }}+I_{i}^{\text {Row }}+G_{i}^{\text {Row }}\right)\right] \\
& +\operatorname{Tax}_{l a b}+\tau_{c a p} \cdot r \cdot P I \cdot A_{F r-F r}+\sum_{i} w \cdot\left(\cot _{p a t r}+\cot _{\text {empl }}\right) \cdot L_{i} \\
& -\left(P_{g} \cdot G+r \cdot B+\Gamma_{m s}+\Gamma\right)
\end{aligned}
$$

This equation determines the public savings $S_{G}$.

\section{A.2.10 Balance of payments}

The balance of payments states that the current account surplus plus the capital account surplus must be equal to zero. In particular, the current account surplus is given by the net exports plus the net factor incomes from the rest of the world, while the capital account surplus is given by the net capital inflows, i.e. the difference between the flow of foreign assets to France $\Delta A_{R o w-F r}$ and the flow of domestic assets to the rest of the world $\Delta A_{F r-R o w}$.

$$
\begin{aligned}
& {\left[\sum_{i} P_{i}^{h} \cdot\left(E_{i}^{E z}+E_{i}^{R o w}\right)\right]-\left[\sum_{i}\left(\sum_{j} P Z_{i}^{f} \cdot Z_{i j}^{f}\right)+P C_{i}^{f} \cdot C_{i}^{f}+P I_{i}^{f} \cdot I_{i}^{f}+P G_{i}^{f} \cdot G_{i}^{f}\right] } \\
+ & {\left[w^{E z} \cdot L_{F r-E z}+r^{R o w} \cdot \varepsilon \cdot P I \cdot A_{F r-R o w}\right]-\left[w \cdot\left(1-c o t_{\text {empl }}\right) \cdot L_{R o w-F r}+r \cdot P I \cdot A_{\text {Row }-F r}\right] } \\
+ & P I \cdot\left(\Delta A_{\text {Row }-F r}-\Delta A_{F r-R o w}\right) \\
= & 0
\end{aligned}
$$

Given that the nominal exchange rate $\varepsilon$ is assumed to be exogenous and the flow of domestic assets $\Delta A_{F r-R o w}$ to the rest of the world is determined by the optimal asset allocation (see infra), the balance of payments determines the flow of foreign assets to France $\Delta A_{R o w-F r}$.

\section{A.2.11 Optimal asset allocation}

The (exogenous) initial wealth owned by French households $\left(A_{F r}\right)$ must be invested, at the beginning of the period, in France or abroad. We suppose that domestic and foreign assets are not perfect substitutes and that the optimal allocation depends on the ratio between the rates of return on the two assets. In

\footnotetext{
${ }^{20}$ The propensity to save is endogenous since the total consumption of the "microsimulation goods" is fixed at the level determined in the Microsimulation model and the total consumption of the "CGE goods" is determined as a fraction of the disposable income (see Equation 15).
} 
particular, the rate of return on the domestic assets is the (net of depreciation) marginal productivity of capital $r$ and the rate of return on the foreign assets is given by the sum between the foreign interest rate $r^{R o w}$ and the percentage variation of the exchange rate $\frac{\varepsilon-\varepsilon_{-1}}{\varepsilon_{-1}}$.

The optimal allocation of the initial wealth, that depends on the anticipated ratio between the two rates of return, is given by:

$$
\begin{aligned}
\frac{A_{F r-F r}}{A_{F r-R o w}} & =\alpha_{F r} \cdot\left(\frac{r}{r^{R o w}+\frac{\varepsilon-\varepsilon_{-1}}{\varepsilon_{-1}}}\right)^{\sigma_{r}} \\
A_{F r} & =A_{F r-F r}+A_{F r-R o w}
\end{aligned}
$$

The previous equations determine $A_{F r-F r}$ and $A_{F r-R o w}$.

The total wealth owned by the representative agent at the beginning of the next period $A_{F r_{+1}}$ must also be allocated between domestic assets and foreign assets. The households total wealth available at the beginning of the next period depends on the private savings and is given by:

$$
P I \cdot A_{F r_{+1}}=P I \cdot A_{F r}+S_{H}
$$

The optimal allocation of $A_{F r_{+1}}$ between domestic assets and foreign assets is made on the basis of the (anticipated) ratio between the rates of return. In particular, the anticipated rate of return on the domestic assets is the anticipated (net of depreciation) marginal productivity of capital $E\left[r_{+1}\right]$ and the anticipated rate of return on the foreign assets is given by the sum between the anticipated foreign interest rate $E\left[r_{+1}^{R o w}\right]$ and the anticipated percentage variation of the exchange rate $E\left[\frac{\varepsilon_{+1}-\varepsilon}{\varepsilon}\right]$. We consider extrapolative expectations, implying that $E\left[r_{+1}\right]=r, E\left[r_{+1}^{R o w}\right]=r^{R o w}$ and $\frac{E\left[\varepsilon_{+1}\right]-\varepsilon}{\varepsilon}=\frac{\varepsilon-\varepsilon}{\varepsilon}=0$. Thus:

$$
\begin{aligned}
\frac{A_{F r-F r_{+1}}}{A_{F r-R o w+1}} & =\alpha_{F r} \cdot\left(\frac{r}{r^{R o w}}\right)^{\sigma_{r}} \\
A_{F r+1} & =A_{F r-F r_{+1}}+A_{F r-R o w_{+1}}
\end{aligned}
$$

The previous equations determine $A_{F r-F r_{+1}}$ and $A_{F r-R o w_{+}}$. The flow of assets to the rest of the world is then given by:

$$
\Delta A_{F r-R o w}=A_{F r-R o w+1}-A_{F r-R o w}
$$

\section{A.2.12 Equilibrium conditions}

\section{A.2.12.1 Markets of goods and services}

At the equilibrium, the quantity produced in each sector $Y_{i}$ must be equal to the domestic and foreign demands:

$$
Y_{i}=X_{i}^{h}+E_{i}^{E z}+E_{i}^{R o w}
$$

This equation determines the domestic equilibrium price in each sector $P_{i}^{h}$.

\section{A.2.12.2 Labor market}

In the labor market, the total labor demanded by all the sectors must be equal to sum between the quantity of labor supplied by French people (that depends on the quantity of labor, determined in the 
Microsimulation model, that French people want to supply $L_{F r-F r}$, and on the unemployment rate $u$ ) and the (exogenous) quantity of labor supplied by foreign people $L_{R o w-F r}$ :

$$
\sum_{i} L_{i}=L_{F r-F r} \cdot(1-u)+L_{R o w-F r}
$$

This equation determines the equilibrium domestic wage $w$.

\section{A.2.12.3 Capital market}

At the equilibrium, the total capital demanded by all the sectors and by the government must be equal to the capital supplied by French people (that depends on the quantity that is endogenously determined in order to optimally allocate the initial wealth) and by foreign people (that is exogenous):

$$
\sum_{i} K_{i}+B=A_{F r-F r}+A_{R o w-F r}
$$

This equation determines the equilibrium domestic rate of remuneration of capital $r$.

\section{A.2.13 Numéraire}

The Walras Law implies that one equation of the model is redundant and one price must be chosen as numéraire. We chosen the domestic consumer price index as the numéraire. Thus, the depreciation of the nominal exchange rate, that is the macroeconomic shock simulated in this paper, implies a depreciation of the same magnitude of the real exchange rate.

\section{A.2.14 Macro closure}

In our CGE model us use a closure rule which is between the neoclassical and the keynesian ones. In particular, we introduce in our model an investment function which takes into account for the (partial) crowding-out effect on investments produced by a change in the components of the aggregate demand. The investment function introduced in our CGE model is the following:

$$
I=\alpha_{0}+\alpha_{1} \cdot G D P_{\text {real }}+\alpha_{2} \cdot r(-4)+\alpha_{3} \cdot C+\alpha_{4} \cdot G+\alpha_{5} \cdot C A
$$

where the parameters have been estimated using quarterly French data from 1960 to 2011 . The results, reported in Table A.2, show that an increase in each of the components of the aggregate demand (consumption $C$, public expenditures $G$, and current account $C A$ ) produces a crowding-out effect on aggregate investments, but this crowding-out effect is only partial, i.e. is less important that the effect obtained using a neoclassical closure. The introduction of this investment function allows us to build a CGE model with a macro closure that is between the neoclassical and the keynesian ones. 
Table A.2: Estimation results of the investment function

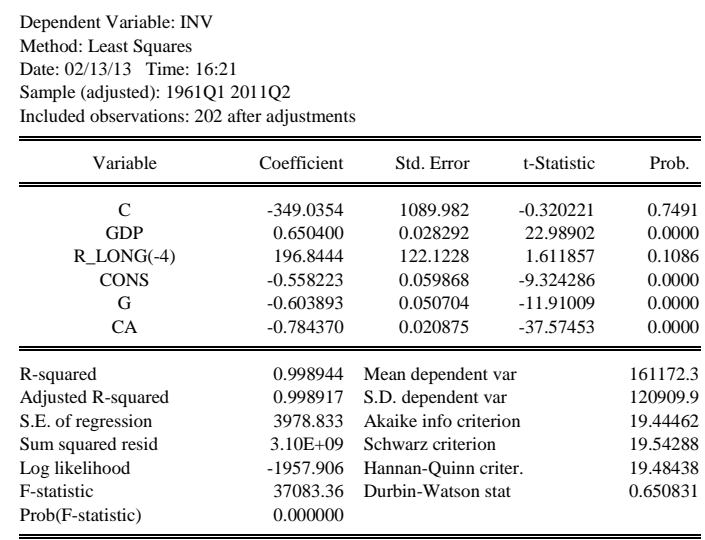

Source: Insee. French data from 1961q1 to 2011q2.

The macroeconomic equilibrium condition states that aggregate investments must be equal to aggregate savings (i.e. the savings of the representative agent, of the government and with respect to the rest of the world):

$$
P I \cdot I=S_{H}+S_{G}+P I \cdot\left(\Delta A_{\text {Row }-F r}-\Delta A_{F r-R o w}\right)
$$

This equation determines the equilibrium unemployment rate $u$.

\section{A.3 Interactions with the Microsimulation model}

Our Micro-Macro model works as follows. First, the CGE model simulates a shock (that can be a macroeconomic or a microeconomic shock) and determines the macroeconomic effects, in particular the percentage variations of (i) the equilibrium domestic wage, (ii) the equilibrium consumer prices of the goods and services, (iii) the consumer price index, and (iv) the unemployment rate.

$$
\begin{aligned}
\Delta \% w & =\frac{w(\text { new })-w(0)}{w(0)} \\
\Delta \% P C_{i} & =\frac{P C_{i}(\text { new })-P C_{i}(0)}{P C_{i}(0)} \\
\Delta \% C P I & =\frac{C P I(\text { new })-C P I(0)}{C P I(0)} \\
\Delta \% u & =\frac{u(\text { new })-u(0)}{u(0)}
\end{aligned}
$$

where $w(0)$ and $w(n e w)$ indicate respectively the initial value (i.e. before the simulation of a shock) and the final value (i.e. the solution value obtained in the CGE model) of the domestic wage rate; $P C_{i}(0)$ and $P C_{i}($ new $)$ are respectively the initial value and the final value of the average consumption price of 
good $i$ (computed as the average between the domestic consumption price and the foreign consumption price); $C P I(n e w)$ and $C P I(0)$ are respectively the initial value and the final value of the consumer price index; $u(n e w)$ and $u(0)$ are respectively the initial value and the final value of the unemployment rate.

The variations of the equilibrium prices are then introduced in the Microsimulation model in order to compute the effects on (i) the total quantity of labor that French people want to supply $L_{F r-F r}$, (ii) the consumption demand of goods and services $C_{i}^{m s}$, (iii) the total tax on labor incomes $\operatorname{Tax}_{\text {lab }}$, (iv) the total contributions paid by the employees and the workers, and (v) the total transfers paid by the government to households $\Gamma_{m s}$.

The percentage variations computed in the Microsimulation model allow us to determine the new value of the exogenous variables in the CGE model as follows:

$$
\begin{aligned}
& L_{F r-F r}(n e w)=\left(1+\Delta \% L_{F r-F r}\right) \cdot L_{F r-F r}(0) \\
& C_{i}^{m s}(\text { new })=\left(1+\Delta \% C_{i}^{m s}\right) \cdot C_{i}^{m s}(0) \\
& \operatorname{Tax}_{l a b}(\text { new })=\left(1+\Delta \% \operatorname{Tax}_{l a b}\right) \cdot \operatorname{Tax}_{l a b}(0) \\
& \cot _{\text {patr }}(\text { new })=\left(1+\Delta \% \operatorname{Tot}_{\text {Cot }} \text { patr }\right) \cdot \cot _{\text {patr }}(0) \cdot \frac{w(0) \cdot\left[L_{F r-F r}(0) \cdot(1-u(0))+L_{\text {Row }-F r}\right]}{w \cdot\left[L_{F r-F r}(\text { new }) \cdot(1-u(n e w))+L_{\text {Row }-F r}\right]} \\
& \cot _{\text {empl }}(\text { new })=\left(1+\Delta \% \operatorname{Tot} C o t_{\text {empl }}\right) \cdot \cot _{\text {empl }}(0) \cdot \frac{w(0) \cdot\left[L_{F r-F r}(0) \cdot(1-u(0))+L_{R o w-F r}\right]}{w \cdot\left[L_{F r-F r}(\text { new }) \cdot(1-u(n e w))+L_{R o w-F r}\right]} \\
& \Gamma_{m s}(\text { new })=\left(1+\Delta \% \Gamma_{m s}\right) \cdot \Gamma_{m s}(0)
\end{aligned}
$$

where $L_{F r-F r}(0)$, is the initial value (i.e. before the simulation of a shock) of the number of French people who want to work in France, $C_{i}^{m s}(0)$ is the initial value of the consumption level for the "microsimulation goods", $\Gamma_{m s}(0)$ is the initial value of the transfers from the government to the households, $\operatorname{Tax}_{l a b}(0)$ is the initial value of the total labor income taxes, $w(0)$ is the initial value of the domestic wage, $\cot _{p a t r}(0)$ and $\cot _{\text {empl }}(0)$ are the initial values of the contribution rates paid respectively by the employers and the employees.

The CGE model is then solved by considering the new values of the exogenous variables determined in the Microsimulation model. The solution obtained in the CGE model (i.e. the percentage variations of the equilibrium prices and the unemployment rate) is then introduced in the Microsimulation model. And so on. We developed an algorithm in which the iterations are stopped when the fixed point is reached, i.e. when all the percentage variations remain (sufficiently) constant from one iteration to another. 